\title{
Escuelas y políticas educativas en la provincia de Cartagena entre 1903-1919
}

\author{
Rafael Enrique Acevedo Puello ${ }^{(*)}$
}

Recibido: junio de 2011

Aprobado: septiembre de 2011

\begin{abstract}
Resumen
Este artículo estudia la escuela como escenario de aprendizaje y formación de los ciudadanos en la Provincia de Cartagena entre 1903-1919. Nos interesa demostrar que la departamentalización de la educación, tras la emisión de la Ley Orgánica de Instrucción Pública de 1903, afirmó el estatus de Cartagena como capital de la educación pública primaria en el Departamento de Bolívar, preponderancia educativa y en la organización de los contenidos temáticos en los colegios por medio de los que se trataba de dar la sensación del progreso, bienestar y adelanto cultural luego de cien años de vida independiente republicana. Por ello, a los escolares les incumbía realizar actividades artísticas, literarias e históricas atinentes a la emancipación para dar muestras de cierta pertenencia social por su lugar de origen y para llegar a ser reconocidos como ciudadanos dignos una vez terminara su ciclo educativo.
\end{abstract}

\section{Palabras Claves}

Escuela primaria, ciudadanía, patria, sujetos letrados, pedagogía cívica, fiesta centenaria.

\section{Summary:}

To study the school like a setting of learning and formation of the citizens is the attentions focus of this article. For this we study the public primary introduction and the educatifs solitics asided for formation of citizens. En the province of Cartagena between 1903-1919. We're interested to show how the departmental character of education, after the emission of the status of Cartagena like the capital of public primary education in the Bolivar`s administrative district, educative preponderance and in the organization of thematic contents in those schools by means of them, they tried to give a progress sensation, wellbeing and cultural advance after one hundred years of republican independent life. That's why the futures citizens, pupils, they had the responsibility to entre at those institution and to do some artistic activities, literaries and historic relating to emancipation, to give samples of social ownership to their original place and to get to be regonized like honourables citizens when the educator cycle finish.

\section{Keys words:}

Primary school, citizenship, native country, civic pedagogy, centenary celebration, learned people.

\footnotetext{
${ }^{(*)}$ Historiador de la Universidad de Cartagena. Candidato a Magister en Historia por la Universidad Nacional de Colombia (sede Bogotá). Actualmente cursa estudios de doctorado en historia en la Universidad de los Andes. Ha publicado "La fiesta del primer centenario de la Independencia de Cartagena de Indias", en Elizabeth Cunin y Edgar Gutiérrez (comps.), Fiestas y Carnavales en Colombia. La puesta en escena de las identidades (Medellín, La Carreta Social, 2006). Se ha desempeñado como docente del Programa de Historia de la Universidad de Cartagena y es miembro del grupo de investigaciones Frontera, sociedad y cultura integrado por docentes de esta unidad académica, categoría B, clasificación Colciencias. rafacep@hotmail.com
} 
"La escuela debe ser el negocio de todos los hombres, porque encierra el progreso de la humanidad de todos los ciudadanos, porque personifica la patria, y de gobierno y pueblo unidas en común esfuerzo, porque de la escuela desciende el espíritu de paz y de amor que hace el engrandecimiento de las naciones de la República. La escuela es como la materia prima de la democracia, sin ella, es una aspiración imposible de la soberanía del pueblo"".

\section{Presentación}

$\mathrm{E}$ 111 de noviembre de 1911, el día de la celebración del primer centenario de la declaratoria de independencia en la provincia de Cartagena, en uno de los salones del Palacio de Gobierno debía exhibirse un Museo Escolar para rendir culto patriótico a la libertad, el avance, la riqueza y "la efectividad de los derechos del hombre dejando de ser esclavos para ser ciudadanos"2. En este acto público debía presentarse por los estudiantes y maestros los materiales de enseñanza objetiva (cuadros, pinturas y mapas), elementos de física, química, arquitectura, cerámica, educación de los sentidos y todo en cuanto a arte manual y libros de historia que personificaran la transformación y el adelanto cultural de la provincia de Cartagena ${ }^{3}$. Pero más que representar el pasado, estos "actos patrióticos", como se le llamaba entonces a toda manifestación cultural referida al centenario, debían servir también para mostrar el progreso educativo, cívico y espiritual de la patria tanto cartagenera como colombiana ${ }^{4}$. Por ello, aparte de las edificaciones del teatro municipal y el parque del centenario, el gobernador, Rafael Calvo C., se dio a la tarea de construir dos Escuelas Modelos avaluadas en \$ 10.000 para ilustrar con "gran pompa" de detalles el desarrollo educativo del territorio bajo su jurisdicción política ${ }^{5}$.

\footnotetext{
${ }^{1}$ Biblioteca Nacional de Colombia [BNC], "La escuela primaria", en El Porvenir, Cartagena, septiembre 3 de 1910. Para la época las escuelas primarias estaban divididas en elementales y superiores. Con la noción de escuela primaria, por lo tanto, haremos alusión tanto a las instituciones básicas como superiores, en las que evidentemente los contenidos de enseñanza impartidas en ellas eran los mismos; quizás la única diferencia era el grado de intensificación horaria de las clases y los temas de estudios en la escuela superior.

2 BNC, “Ordenanza 68, sobre celebración del centenario de la independencia de Cartagena", en Gaceta Departamental de Bolivar, Cartagena, mayo 12 de 1911.

${ }^{3}$ BNC, "Programa de las festividades que se celebraran en los días 10, 11, 12, 13, 14, 15, 16, 17, 18, y 19 de noviembre para conmemorar el primer centenario de independencia absoluta de la Provincia de Cartagena de Indias", en El Porvenir, Cartagena, noviembre 5 de 1911.

${ }^{4}$ En este sentido, la noción de patria hacía referencia tanto al progreso de la localidad como de la república colombiana. BNC, "El concepto de patria", en El Porvenir, Cartagena, marzo 22 de 1910. Maurizio Viroli, Por amor a la patria: un ensayo sobre el patriotismo y el nacionalismo, Madrid, Acento Ed., 1997, pp.16 y ss.

${ }^{5}$ BNC, "Ordenanza 68, sobre celebración del centenario de la independencia de Cartagena”, p. 373. Tanto fue así que, en una crónica periodística posterior, un autor anónimo hacia una crítica al gobernador por proyectar las dos "Escuelas Modelos" en un terreno cercano a las murallas, el mercado y la estación del ferrocarril que, además de obstruir la ventilación de esos sendos establecimientos de instrucción pública, no contaba esta zona con las condiciones higiénicas, ambientales y auditivas apropiadas para impartir clases. En la nota, no obstante, se decía que: "el señor Gobernador, que además de ser persona ilustrada,
} 
Por consiguiente, la inauguración de nuevas escuelas representaba la idea de progreso, engrandecimiento y adelanto cultural trasmitida por las autoridades locales y nacionales para dar la sensación de pertenecer a una misma patria e identidad política luego de cien años de vida republicana ${ }^{6}$. Luego de los enfrentamientos civiles decimonónicos y de la secesión de Panamá, en efecto, en las escuelas primarias recaía la esperanza de construir un modelo de ciudadano colombiano, cuyas características de este era ser un "sujeto letrado" que supiera leer y escribir, o poseer por lo menos una profesión, arte u oficio legitimo para subsistir con tal de poder participar en los procesos democráticos del país ${ }^{7}$. Estos planteles educativos, por ende, empezaban a convertirse en los escenarios propicios para instruir, educar y trasformar a los escolares en ciudadanos, objetivo este que debía llevarse a cabo a través de la ilustración de los atributos de la identidad del "hombre perfecto", es decir, del "hombre colombiano" que debía poseer ciertos connotaciones nacionales como: el reconocimiento del idioma español, la religión católica y la pertenecía a un mismo pasado nacional ${ }^{8}$. "Ser, sentirse y hacerse ciudadano" era adiestrarse y reconocerse como colombiano. A los estudiantes, por lo tanto, les tocaba asistir a las escuelas y participar activamente en las jornadas, tareas y actividades pedagógicas para educarse "gradualmente en todos los derechos y funciones que forman la nacionalidad y la ciudadanía" ${ }^{\text {. No entrar }}$ a esos espacios de aprendizaje, en consecuencia, era exponerse a ser objeto de calificativos por parte de la prensa oficial como "vagabundos", "mendigos" y "marginales" de todo tipo

es médico, podrá juzgar si estas son condiciones higiénicas para una escuela moderna". En efecto, el discurso de la escuela por aquella época llevaba implícita una concepción por lo moderno articulado a la idea del bienestar, el progreso y el adelanto cultural de la Provincia de Cartagena. BNC, "Centenario de Cartagena. Las escuelas modelos", en El Porvenir, Cartagena, junio 3 de 1911.

${ }^{6}$ Las escuelas, vistas así, eran los escenarios sociales de aprendizajes indispensables para la vida profesional y el espacio ideológico propicio para enseñar la identidad del ciudadano como un sujeto colombiano obediente a las instituciones políticas del país al cual pertenecía. Sobre esta caracterización de las escuelas nos apoyamos en: Michel de Certeau, La cultura en plural, Buenos Aires, Nueva Visión, 1999, p. 106. Del mismo modo ver: BNC, "Educación e instrucción”, en El Porvenir, Cartagena, marzo 22 de 1910, p.2.

${ }^{7}$ El concepto político del ciudadano colombiano como un "sujeto letrado" lo construimos con base a lo dispuesto en los artículos 15 de la constitución política de 1886 y el artículo 44 del acto legislativo de 1910, en los que evidentemente se establecía que para pretender alcanzar la ciudadanía o la calidad de nacional colombiano, tales pretendientes debían ser profesionales, cultos, saber leer y escribir. Esta legislación puede consultarse en: Miguel Antonio Pombo y José Joaquín Guerra (comps.), Constituciones de Colombia, tomo IV, Bogotá, Biblioteca Popular de Cultura Colombiana, 1951, pp. 210, 219 y 326.

${ }^{8}$ El idioma, el pasado y la religión, tal como lo ha sugerido Eric Hobsbawm, constituyen los valores primordiales para inventar cierta identidad nacionalista, cuyo propósito y novedad consiste en dar la sensación de pertenecer a una misma comunidad política. Eric Hobsbawm, Los ecos de la Marsellesa, Barcelona, ed. Critica, pp. 101-130. Eric Hobsbawm y Ranger Terence, (eds.), The invention of tradition, Cambridge University Press, 1983. Mientras que sobre la consideración de un modelo de hombre colombiano ver: Martha Herrera, "Debates sobre raza, nación y educación: ¿hacia la construcción de un 'hombre nacional'?", en Martha C. Herrera y Carlos Jilmar (comps.), Educación y cultura política: una mirada multidisciplinaria, Bogotá, Universidad Pedagógica Nacional, 2001, pp.117-142. José Grau, Catecismo político. Arreglado a la constitución de la República de Colombia (de 30 de agosto de 1821). Para el uso en las escuelas de primeras letras del Departamento del Orinoco, Bogotá, Imprenta de la República, 1824, pp. 13-30.

${ }^{9}$ BNC, Pedro M. Carreño, “La política en los planteles de educación”, en El Porvenir, Cartagena, junio 24 de 1911. Marta Herrera y otros, La identidad nacional en los textos escolares de ciencias Sociales. Colombia 1900-1950, Bogotá, Universidad Pedagógica Nacional, 2003, pp. 49-69. 
por constituir la antítesis del discurso moderno de civilidad propuesto por el gobierno nacional y local. Así pues, la ciudadanía terminaba siendo una práctica privilegiada, muy amplia ciertamente, pero privilegiada para el prototipo del individuo educado, productivo y provechoso para la sociedad ${ }^{10}$.

En este artículo, por lo tanto, estudiaremos cuáles fueron las imágenes del ciudadano moderno que operaban en las políticas educativas de principios del siglo XX, por lo que se hace necesario preguntarnos también: ¿cómo era el movimiento de instrucción pública primaria en la provincia de Cartagena entre 1903-1919?, es decir, ¿con qué tipo de escuelas y alumnos se contaban para emprender el proceso de educación del ciudadano moderno?, ¿bajo qué condiciones estudiaban? y ¿qué implicaciones traía el hecho de asistir o no a los colegios? Pretendemos así hacer una caracterización de la Ley Orgánica de Instrucción Pública de 1903 (que se mantendría vigente hasta 1930) y de los colegios de la básica primaria en la provincia de Cartagena ${ }^{11}$, para develar como esta localidad durante el centenario va a constituirse en la capital de la educación pública elemental en el Departamento de Bolívar, en el lugar donde los alumnos asistían para formarse como ciudadanos, para adscribirse a las escuelas y participar activamente en la celebración del centenario de la independencia. Estas características hacían de las escuelas en la provincia Cartagena, por ende, el escenario propicio para representar la idea de adelanto cultural asociada a las celebraciones patrias de 1911.

\section{Las escuelas primarias en la Provincia de Cartagena a finales del siglo XIX y principios del $\mathrm{XX}$}

A finales del siglo XIX y principios del XX, en medio de dos guerras civiles, la separación de Panamá y las conmemoraciones del primer centenario de la independencia, el movimiento de instrucción pública primaria no era para nada invariable en la provincia de Cartagena $^{12}$. Si bien, el número de escuelas y estudiantes matriculados en esta localidad sobrepasaba al registrado para las provincias de Mompox, Barranquilla y las Sabanas entre 1893-1895(ver tabla 1), lo es también el hecho de que esta preponderancia de alumnos y

\footnotetext{
${ }^{10}$ François-Xavier Guerra, "El soberano y su reino. Reflexiones sobre la génesis del ciudadano en América Latina", en Hilda Sabato (comp.), Ciudadanía política y la formación de las naciones. Perspectivas históricas de América Latina, México, El Colegio de México-FCE, 1999, p. 33. La ciudadanía, en este sentido, era una práctica pedagógica destinada a la formación de un nuevo hombre republicano identificado con las instituciones políticas de su sociedad. François-Xavier Guerra, Modernidad e independencias. Ensayos sobre las revoluciones hispanoamericanas, México, FCE, 1992, p. 13. Beatriz González, "Modernización y disciplinamiento del cuerpo. La formación del ciudadano en el espacio público y privado", en Beatriz González (comp.), Esplendores y miserias del siglo XIX. Cultura y sociedad en América Latina, Caracas, Monte Ávila eds., 1994.

${ }^{11}$ Aunque es menester anotar que existieron otras disposiciones sobre Instrucción Pública, como el decreto 491 de 1904, el decreto 827 de 1913, entre otros, que eran una extensión de la Ley de 1903. De allí nuestro interés por profundizar en esta última. Sobre estos decretos ver: M. Herrera y otros, La identidad nacional en los textos escolares de ciencias Sociales. Colombia 1900-1950, pp. 49-69.

${ }^{12}$ Este movimiento de instrucción pública podemos consultarlo en José P. Urueta y Eduardo G Piñeres, Cartagena y sus Cercanías, Cartagena, Imp. Departamental, 1912, pp. 232-300.
} 
establecimientos educativos no fue una constante durante ése periodo. En 1896, por ejemplo, la provincia de Cartagena dejaría de ser, por un lado, el escenario donde había más colegios de la básica primaria con tan sólo 19 instituciones y por otro, la segunda en cuanto al número de educandos activos ${ }^{13}$. Barranquilla, hasta entonces provincia perteneciente al Departamento de Bolívar, donde la inversión de capitales extranjeros hubo de favorecer su infraestructura escolar, igualaba la cantidad de establecimientos educativos de Cartagena y, del mismo modo, superaba en al menos 71 escolares la cifra de educandos matriculados $^{14}$. De modo que, difícilmente, en el Departamento de Bolívar había una primacía regional de alguna de sus provincias como médula de la educación básica primaria en las dos últimas décadas del siglo XIX.

Tabla $1^{15}$

Escuelas primarias y estudiantes matriculados en las Provincias de Cartagena, Barranquilla, Sabanas y Mompox, entre 1893-1896.

\begin{tabular}{|c|c|c|c|}
\hline Años & Provincia & Número de escuelas & Número de matriculados \\
\hline \multirow{4}{*}{$\begin{array}{c}1893 \\
\text { a mayo de } \\
1894\end{array}$} & Provincia de Cartagena & 35 & 2.036 \\
\cline { 2 - 4 } & Provincia de Barranquilla & 29 & 1.423 \\
\cline { 2 - 4 } & Provincia de Sabanas & 23 & 1.914 \\
\cline { 2 - 4 } & Provincia de Mompox & 10 & 3.87 \\
\hline \multirow{2}{*}{$\begin{array}{c}1895 \\
\text { a mayo de } \\
1896\end{array}$} & Provincia de Cartagena & 19 & 9.77 \\
\cline { 2 - 4 } & Provincia de Barranquilla & 19 & 1.048 \\
\cline { 2 - 4 } & Provincia de Sabanas & 22 & 895 \\
\cline { 2 - 4 } & Provincia de Mompox & 11 & 541 \\
\hline
\end{tabular}

Esta variación del número de escuelas y alumnos matriculados se dio en parte por la prolongada situación conflictiva del territorio colombiano al finalizar el siglo XIX. Pues, hasta ese entonces, los establecimientos de educación primaria eran subvencionados con fondos provenientes del tesoro nacional y por ende, esta dependencia administrativa se veía alterada cuando el país entraba en continuas guerras civiles, que no sólo perturbaban la economía, la agricultura y el normal funcionamiento de las cajas nacionales, sino que también demandaban de una mayor inversión de capitales en armas y municiones antes que

${ }^{13}$ Muy a pesar de que el inspector provincial de instrucción pública departamental, Miguel de la Vega, contabilizaba 29 instituciones primarias en su informe del 4 de mayo de 1896, habían sólo 19 escuelas con alumnos matriculados y por ende, estos colegios eran los únicos que estaban funcionado académicamente, pues en las otras diez no había presencia de escolares y como tal sus labores académicas, más no administrativas, eran casi que nulas. Miguel de la Vega, Memoria que presenta el secretario de instrucción pública al señor gobernador del departamento en el año de 1896, Cartagena, Tip. Araujo, 1896, pp. 10, 60-61.

14 Juan Guillermo Restrepo, "Educación y desarrollo en Barranquilla a finales del siglo XIX", en Jorge Villalón (comp.), Historia de Barranquilla, Barranquilla, eds. Uninorte, 2000, pp. 153-182. Mientras en las provincias de sabanas parecía no variar el número de escuelas pero si reducirse la cifra de estudiantes matriculados.

${ }^{15}$ Fuentes: Luis Patrón, Memoria que presenta el Secretario de Instrucción Pública al Señor Gobernador del Departamento de Bolívar en el año de 1894, Cartagena, Tip. Araujo, 1894, pp. 3-50. BNC, M. de la Vega, Memoria que presenta el secretario de instrucción pública al señor Gobernador del departamento en el año de 1896, pp. 60-61, 64-69, 72-80, 98-99. 
en enseres escolares ${ }^{16}$. Además, en cualquier momento los colegios podían ser clausurados como producto de las asonadas civiles vividas en la república ${ }^{17}$. La Guerra de los Mil Días (1899-1902), por ejemplo, dio al traste con la clausura de varias escuelas por la falta de fondos públicos para subvencionar su mantenimiento, pero igualmente por la insuficiencia de estudiantes en las pocas escuelas abiertas, pues los niños y jóvenes eran víctimas de un reclutamiento forzoso en los ejércitos liberales y conservadores ${ }^{18}$.

La vulnerabilidad escolar causada por los efectos de las guerras civiles a finales del siglo XIX hubo de sentirse con mayor fuerza en la utilización de algunos espacios de educación como "servicios de cuartel", tal como sucedió con la Escuela Normal de Cartagena, clausurada y convertida en centro de operaciones militares en $1895^{19}$. El servicio a la patria en tiempos de guerra daba al traste entonces con los desequilibrios en materia de inversión en educación y por ende, la clausura de varias instituciones de la básica primaria. En la provincia de Cartagena, no obstante, serían suprimidos varias instituciones privadas como el Colegio de Tatis, de María Auxiliadora, de María, de San Fernando, de Heredia, de Nuestra Señora del Socorro, de Colón y Universitario de Bolívar, por la falta de recursos que garantizaran el pago de los costos acarreados por el arriendo de locales, los salarios de docentes y los enseres escolares ${ }^{20}$. Una muestra de esta situación se aprecia en la tabla dos, el cual fue elaborado por el Inspector Escolar Miguel de la Vega en el año de 1896 para hacer un llamado de atención sobre la desproporción entre los gastos públicos y el número de escuelas en el Departamento de Bolívar.

\footnotetext{
${ }^{16}$ Aline Helg, La educación en Colombia 1918-1957: una historia social, económica y política, Bogotá, Cerec, 1987, pp. 30-31.

${ }^{17}$ Esta situación conflictiva también conllevó al extravió de los archivos escolares, la falta de registro de algunos colegios del distrito y la precariedad de los balances educativos por las condiciones no apropiadas para escribirlos por parte de los secretarios de instrucción pública del Departamento de Bolívar. Estos inconvenientes nos impiden hacer un rastreo completo y exhaustivo sobre el número de escuelas y estudiantes en las dos últimas décadas del siglo XIX. M. de la Vega, Memoria que presenta el secretario de instrucción pública al señor gobernador del departamento en el año de 1896, pp. 9, 57-58. Sobre estos temas también ver: Eduardo Posada, El Caribe Colombiano. Una invitación a la historia regional (18701950), Bogotá, Banco de la República-El Áncora eds., 1997, pp. 33-38.

18 Carlos Eduardo Jaramillo, "Guerra de los mil días: reclutamiento, ascenso y deserciones". http://www.lablaa.org /blaavirtual/revistas/credencial/enero2000/121guerra.htm. (Consulta: abril 8 de 2007).

${ }^{19}$ M. de la Vega, Memoria que presenta el secretario de instrucción pública al señor gobernador del departamento en el año de 1896, pp. 8-10.

${ }^{20}$ J. Urueta y E. Piñeres, Cartagena y sus Cercanías, pp. 278 y 279. Sobre la poca escolarización y alfabetización en el Departamento de Bolívar, ver: A. Helg, La Educación en Colombia: 1918-1957, pp. $42-47$.
} 
Tabla $2^{21}$

Movimiento de Instrucción Pública Primaria y gastos educativos en alguna de las provincias del Departamento de Bolívar en febrero de 1896.

\begin{tabular}{|l|c|c|c|c|c|c|c|c|}
\hline \multicolumn{1}{|c|}{ Provincia } & Varones & Niñas & Total & Alternadas & Nocturnas & Rurales & Total & Gastos \\
\hline Barranquilla & 8 & 8 & 16 & & 1 & 2 & 19 & $\$ 8.232$ \\
\hline Carmen & 6 & 6 & 12 & & & & 12 & $\$ 3.312$ \\
\hline Cartagena & 13 & 13 & 26 & 3 & 2 & 2 & 33 & $\$ 10.404$ \\
\hline Lorica & 8 & 7 & 15 & & & 2 & 17 & --- \\
\hline Mompox & 10 & 9 & 19 & & & 1 & 20 & $\$ 8.554$ \\
\hline Sabanas & 14 & 11 & 25 & & & & 25 & $\$ 7.656$ \\
\hline Total & 59 & 54 & 113 & & & & 126 & $\$ 37.648$ \\
\hline
\end{tabular}

De acuerdo con la tabla 2, en la Provincia de Cartagena anualmente el gobierno nacional, con caudales del departamento, aportaba la módica suma de \$ 10.404 para subvencionar el pago de los locales, la nomina de profesores y los útiles escolares en las 33 escuelas primarias contabilizadas por los Inspectores Escolares Joaquín F. Vélez y Pablo J. Bustillo, a finales de $1896^{22}$. Con esta cantidad se debía comprar pizarras, reglas, tizas, cuadernos y textos escolares, pagar los sueldos de los directores y subdirectores, y en fin, manumitir todos los gastos en materia de enseñanza para dar la sensación de poseer colegios aptos para la formación de los escolares. Pero lo común era encontrar estos establecimientos educativos sin maestros, sin sillas, sin mobiliarios y sin las condiciones apropiadas para desarrollar el proceso formativo de los estudiantes ${ }^{23}$. Esta situación, por ejemplo, se evidenció en uno de los informes de Instrucción Pública, donde se planteaba que:

De 66 distritos que tiene actualmente el Departamento, sólo 36 tienen abiertas escuelas de niñas; y esto, à pesar del tesón de la Secretaria de Instrucción Pública para que se abran las cerradas. Los locales de las escuelas fueron cuarteles en casi todo el Departamento; el mobiliario fue destrozado, y á duras penas sólo se ha podido arreglar en muchas partes el local y mobiliario de las de varones. La pobreza de varios distritos, en donde las rentas no producen ni siquiera para pagar al Juez, ha sido otro obstáculo para la apertura de las escuelas de niñas. Esto sucede, principalmente, en la

${ }^{21}$ Fuentes: BNC, M. de la Vega, Memoria que presenta el secretario de instrucción pública al señor gobernador del departamento en el año de 1896, pp. 10-11. Nota: no se incluye el gasto del Sinú que equivale a $\$ 4.776$, oo que sumado al total general de los costos educativos sería $\$ 42.924$,oo.

22 M. de la Vega, Memoria que presenta el secretario de instrucción pública al señor gobernador del departamento en el año de 1896, pp. 5-13. BNC, Luis Patrón, Memoria que presenta el Secretario de Instrucción Pública al Señor Gobernador del Departamento de Bolivar en el año de 1894, Cartagena, Tip. Araujo, 1894, 102 pp. Cabe anotar que para finales de 1896, cuando la intensidad belicosa parecía detenerse, Cartagena tendría nuevamente 33 escuelas abiertas.

${ }^{23}$ M. de la Vega, Memoria que presenta el secretario de instrucción pública al señor gobernador del departamento en el año de 1896, p. 11. 
Provincia de Mompox, de cuyos 11 distritos sólo 2 tienen abiertas su escuela de niñas ${ }^{24}$.

El Departamento de Bolívar, visto así, no era ajeno entonces a los desequilibrios del número de escuelas y estudiantes matriculados, provocados por la casi nula inversión en materia educativa por parte del gobierno departamental y nacional al finalizar el siglo XIX. De allí que en las escuelas, tanto públicas como privadas, en ocasiones sus directores se vieran en la penosa necesidad de no recibir a los estudiantes por falta de maestros y salones adecuados para desarrollar el proceso educativo.

\section{La reforma educativa de 1903: la departamentalización de la educación y la primacía educativa de la Provincia de Cartagena}

A diferencia de los últimos veinte años del periodo decimonónico, cuando no había una preponderancia estable de alguna de las provincias del Departamento de Bolívar como centro de la educación primaria, la provincia de Cartagena va a convertirse en la médula de este tipo de instrucción básica en las dos primeras décadas del siglo XX. En 1911, por ejemplo, cuando la ciudad estaba preparándose para conmemorar el primer centenario de la independencia, el número de escuelas públicas básicas de carácter urbana era de 34 y las rurales de 18 , es decir, había un total de 52 establecimientos educativos, a los cuales asistían en promedio 4.314 educandos ${ }^{25}$. Estas cifras estaban por encima del total de instituciones educativas y alumnos matriculados en provincias muy cercanas a esa jurisdicción política, como por ejemplo Mompox, Sincelejo, Magangue o El Carmen donde los 4.016 estudiantes activos, que representaban la suma general de escolares inscritos en los colegios de estas tres localidades, ni siquiera lograba superar la cantidad registrada para la capital del Departamento de Bolívar (ver tabla 3). En efecto, allí donde funcionaba la Universidad de Bolívar, hoy Universidad de Cartagena, la enseñanza pública primaria cada vez más sobresalía por su primacía a nivel departamental.

Varias razones ayudan a explicar esta primacía de la provincia de Cartagena como centro de la educación pública primaria en el Departamento de Bolívar a principios del siglo XX. Primero, la apertura de escuelas cerradas por las guerras civiles y la puesta en funcionamiento de otras en corregimientos como Barú, El Guamo y Tolú, conllevarían a

${ }^{24}$ M. de la Vega, Memoria que presenta el secretario de instrucción pública al señor gobernador del departamento en el año de 1896, p. 9.

${ }^{25}$ BNC, "Movimiento de instrucción pública primaria en el Departamento de Bolívar en el año de 1911", en Gaceta Departamental de Bolivar, Cartagena, abril 12 de 1912, p. 478; BNC, "Informe del inspector provincial de Instrucción Pública”, en Gaceta Departamental de Bolívar, Cartagena, enero 12 de 1912, p. 43. J. Urueta y E. Piñeres, Cartagena y sus cercanías, pp. 233-236. En este último texto tan solo se registran 27 instituciones de educación primaria debido a que nada más se contabilizan las escuelas urbanas de Cartagena y de algunos de sus distritos, como Pasacaballo, Bocachica, Barú y Arroyo Grande, no teniéndose en cuenta otras jurisdicciones como Arjona, Calamar, Mahates, San Estanislao, Santa Catalina, Santa Rosa, Soplaviento, Turbaco, Turbana, Villanueva, entre otros pueblos, que también hacían parte de la Provincia de Cartagena. 
una mayor superioridad del número de colegios y alumnos matriculados ${ }^{26}$. Segundo, la erección de Barranquilla como capital del Departamento del Atlántico fundado en $1905^{27}$, significó aligerar las cargas financieras del Departamento de Bolívar, fondos que tradicionalmente eran destinados a otras zonas como Cartagena, que además de ser su capital departamental, estaba preparándose para festejar el primer centenario de su libertad.

Tabla $3^{28}$

Movimiento de la Instrucción Pública Primaria en el Departamento de Bolívar en el año de 1911

\begin{tabular}{|c|c|c|c|c|c|c|c|c|c|c|c|c|c|c|c|c|c|c|c|}
\hline \multirow[b]{3}{*}{ 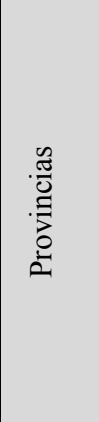 } & \multicolumn{12}{|c|}{ Número de escuelas } & \multicolumn{7}{|c|}{ Alumnos matriculados } \\
\hline & \multicolumn{4}{|c|}{ Rurales } & \multicolumn{4}{|c|}{ Urbanas } & \multicolumn{4}{|c|}{ Totales } & \multicolumn{3}{|c|}{ Rurales } & \multicolumn{3}{|c|}{ Urbanas } & \multirow[b]{2}{*}{ 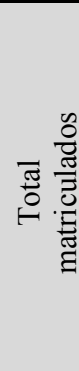 } \\
\hline & 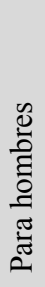 & 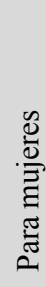 & 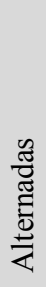 & 胥 & 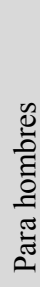 & 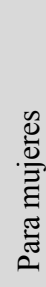 & 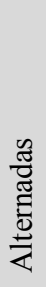 & 亚 & 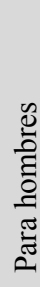 & 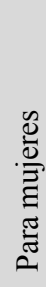 & 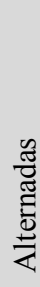 & 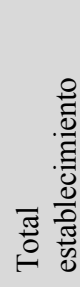 & 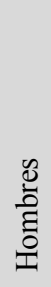 & 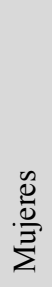 & 퓽 & 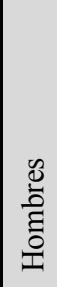 & $\frac{\mathscr{d}}{\stackrel{\mathscr{d}}{\Xi}}$ & $\underset{0}{\tilde{\pi}}$ & \\
\hline Cartagena & 5 & 4 & 9 & 18 & 17 & 17 & - & 34 & 22 & 21 & 9 & 52 & 564 & 559 & 1123 & 1439 & 1752 & 3191 & 4314 \\
\hline Carmen & 1 & 1 & 2 & 4 & 7 & 6 & - & 13 & 8 & 7 & 2 & 17 & 562 & 104 & 156 & 547 & 369 & 916 & 1072 \\
\hline Mompox & 2 & 1 & 3 & 6 & 9 & 9 & - & 18 & 11 & 10 & 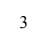 & 24 & 122 & 102 & 224 & 479 & 477 & 956 & 1180 \\
\hline Corozal & 8 & 4 & 1 & 13 & 12 & 8 & - & 20 & 20 & 2 & 1 & 33 & 300 & 240 & 540 & 580 & 515 & 1095 & 1635 \\
\hline Sincelejo & 6 & 1 & 3 & 10 & 14 & 9 & . & 23 & 20 & 10 & 3 & 33 & 181 & 63 & 244 & \begin{tabular}{|l|}
394 \\
\end{tabular} & 626 & \begin{tabular}{|l}
1520 \\
\end{tabular} & 1764 \\
\hline Chinú & - & - & 5 & 5 & 8 & 7 & - & 15 & 8 & 7 & 5 & 20 & 50 & 31 & 81 & 404 & 454 & 858 & 939 \\
\hline Magangue & - & $=$ & 7 & 7 & 5 & 3 & - & 8 & 5 & 3 & 7 & 15 & 200 & 114 & 314 & \begin{tabular}{|l}
156 \\
\end{tabular} & 229 & $\begin{array}{l}385 \\
\end{array}$ & 699 \\
\hline Sinú & 9 & 5 & 2 & 16 & 9 & 7 & 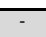 & 16 & 18 & 12 & 2 & 32 & 346 & 222 & 568 & 625 & 560 & \begin{tabular}{|l}
1185 \\
\end{tabular} & 1753 \\
\hline \begin{tabular}{|l|} 
Providencia \\
$\mathrm{s}$
\end{tabular} & - & - & 4 & 4 & & - & - & & & - & & $\theta$ & 98 & 98 & \begin{tabular}{|l}
196 \\
\end{tabular} & & & - & 196 \\
\hline \begin{tabular}{|l} 
Totales \\
\end{tabular} & 31 & 16 & 36 & 83 & 81 & 66 & - & 147 & 112 & 82 & 32 & 226 & 1913 & 1533 & 3446 & 5124 & 4982 & $\begin{array}{c}1010 \\
6\end{array}$ & 13522 \\
\hline
\end{tabular}

Así por ejemplo, el gobernador Rafael Calvo C., destinó la suma de \$10.000,oo para la construcción de dos "escuelas modelos" en esta ciudad en honor a la festividad de $1911^{29}$. Tercero, como consecuencia de lo anterior, esta afirmación departamental de aquella urbe

\footnotetext{
${ }^{26}$ No obstante, las escuelas de estos corregimientos entrarían en funcionamiento a principios del siglo XX luego de permanecer cerradas. Sobre la edificación de estos planteles de enseñanza primaria ver: M. de la Vega, Memoria que presenta el secretario de instrucción pública al señor gobernador del departamento en el año de 1896, p.10.

${ }^{27}$ Aunque, en 1910 fue cuando se consolido definitivamente el Departamento del Atlántico, año este en el cual se crearía también un Centro de Historia para organizar la memoria de Barranquilla. Jorge Villalón, "Barranquilla y sus historiadores", en J. Villalón, Historia de Barranquilla, p. 13.

${ }^{28}$ Fuentes: BNC, "Movimiento de Instrucción Pública Primaria en el Departamento de Bolívar en el año de 1911", en Gaceta Departamental de Bolivar. Cartagena, Abril de 1912, p. 2; "Informe del inspector provincial de Instrucción Pública”, en Gaceta Departamental de Bolívar, Cartagena, 12 de enero de 1912, p.43; J. Urueta y E. Piñeres, Cartagena y sus cercanías, pp. 233-236.

29 “Ordenanza 68, sobre celebración del centenario de la independencia de Cartagena”.
} 
del Caribe colombiano como núcleo de la educación básica, también se vio favorecida por funcionar en ella las Escuelas Normales y la Universidad de Bolívar, donde los estudiantes podían ingresar una vez terminaran su ciclo básico.

De tal suerte que la provincia de Cartagena contaba con las condiciones necesarias para ratificarse como vitrina educativa a nivel departamental, por lo que era imprescindible invertir en la construcción de establecimientos de colegios para dar la sensación de estar progresando:

La Provincia de Cartagena, que puede propiamente llamarse el nervio esencial del ramo, porque en su capital existen las Escuelas Normales, donde se forman los Profesores pedagógicos; y el foco principal de la luz: su antiquísima Universidad, no es de extrañar que arroje un mayor número de alumnos que se instruyan en las escuelas oficiales primarias, prescindencia hecha de la respetable cantidad de niños que acuden en busca de alimento intelectual á los Colegios y pequeñas escuelas privadas ${ }^{30}$.

Estas aseveraciones, que ya venía haciendo el Inspector Escolar Pablo J. Bustillo desde 1896, encontrarían su confirmación en las dos primeras décadas del siglo XX, cuando el gobierno departamental vio en la educación la posibilidad de formar una clase de trabajadores útiles para la provincia de Cartagena ${ }^{31}$. De hecho, tras la emisión de la Ley orgánica de educación pública de 1903, redactada por el entonces Ministro de Instrucción Pública Antonio José Uribe, los departamentos estaban facultados para organizar y pagar con sus propios fondos los gastos demandados por las escuelas primarias de la república ${ }^{32}$. Esta autonomía departamental, por lo tanto, los autorizaba para clausurar o dar apertura a los establecimientos de enseñanza primaria dependiendo de sus intereses administrativos. De manera que, desde ese año y hasta 1930, los salarios de los maestros, los edificios y muebles de este tipo de planteles de enseñanza básica eran subvencionados con capitales provenientes de la localidad donde se residía, por lo que el Departamento de Bolívar se hacía acreedor y responsable del normal funcionamiento de la educación elemental ${ }^{33}$. En otras palabras, la educación primaria terminaba siendo un asunto del departamento, mientras el gobierno nacional nada más se comprometía a supervisar y aportar los materiales escolares cuando las situaciones lo ameritaban.

\footnotetext{
${ }^{30}$ M. de la Vega, Memoria que presenta el secretario de instrucción pública al señor gobernador del departamento en el año de 1896, p. 7. Así pues, mientras Barranquilla iba adquiriendo un sitial como ciudad portuaria, debido al incremento de sus dinámicas comerciales, fabriles, industriales y portuarias, Cartagena era la cuna de la educación superior costeña. E. Posada, El Caribe colombiano, p. 246.

${ }^{31}$ Sergio Paolo Solano, Puerto, sociedad y conflicto en el Caribe colombiano, 1850-1930, Cartagena, Observatorio del Caribe Colombiano-Ministerio de Cultura-Universidad de Cartagena, 2003, pp. 70-71.

${ }^{32}$ Ivon Le Bot, Educación e ideología en Colombia, Bogotá, La Carreta, 1985, p. 15.

${ }^{33}$ BNC, Fernando Gómez Pérez, Memoria que presenta el director general de instrucción pública al Sr. gobernador del Departamento de Bolívar en el año de 1911, Cartagena, imp. Mogollón, 1911, pp. 3-9. "Ordenanza numero 45, sobre creación de una caja de instrucción pública", en Gaceta Departamental de Bolivar, Cartagena, mayo 4 de 1915, p. 5007. A. Helg, La Educación en Colombia: 1918-1957, pp. 102104.
} 
Sin embargo, es menester anotar también que esta autonomía departamental en torno a la organización de la instrucción pública primaria no era novedosa en el Departamento de Bolívar. Puesto que desde el 2 de marzo de 1903, casi ocho meses antes de ser decretada y aprobada (el 26 de octubre de 1903) la Ley Antonio José Uribe, por ejemplo, era emitido un decreto público en el que el hasta entonces gobernador del Departamento de Bolívar, el general cartagenero Luís Vélez R., decretaba y manifestaba su interés por reanudar en algunos de los "municipios más importantes" las tareas de la educación elemental con fondos del tesoro departamental, al considerar:

Que suprimida la enseñanza elemental en los Distritos por la acción de la pasada contienda civil, la Gobernación se halla animada del deseo de hacer reanudar cuanto antes las tareas de la Instrucción primaria;

Que siendo difícil la situación del Tesoro departamental, no es posible por ahora abrir todas las Escuelas sino apenas las de los municipios más importantes del Departamento (...).

Decreta:

Art.1. Procédase á la apertura inmediata de las Escuelas primarias de varones y de niñas de Cartagena, Barranquilla, Sabanalarga, Carmen, Corozal, Sincelejo, Lorica, Magangue y Mompox, y asimismo las de niñas de los Distritos que pueden pagar puntualmente los gastos de demanda el sostenimiento de ella $(\ldots)^{34}$.

Así pues, esta departamentalización de la educación, además de presentarse con anterioridad a la Ley Antonio José Uribe, terminaba también por favorecer la reactivación de la enseñanza primaria en las escuelas urbanas de los distritos más importantes del Departamento de Bolívar. En la provincia de Cartagena y Barranquilla la cancelación de la nomina mensual de los respetivos directores y subdirectores equivalían por persona a 500 pesos; y en las capitales provinciales de El Carmen, Sabanalarga, Corozal, Sincelejo, Lorica, Magangué y Mompox el pago por cada uno de los miembros de la planta directiva de los colegios oscilaba entre los $\$ 300$ y $400 \mathrm{al} \mathrm{mes}^{35}$. De manera que según el decreto 230 reglamentario de instrucción pública emitido por las autoridades locales del Departamento de Bolívar, luego de la culminación de la "Guerra Civil de los Mil Días" en 1902, en mayor medida una de las principales preocupaciones del gobierno departamental era reanudar las tareas escolares para dar la sensación de estabilidad, progreso y engrandecimiento de la patria colombiana desde localidades como Cartagena. En efecto, los nuevos establecimientos de ilustración elemental de la localidad representaban la cobertura y el adelanto educativo, aún cuando en las zonas rurales nada se hacía por invertir y estimular los procesos pedagógicos. Por ello, la departamentalización de la educación, como lo

${ }^{34}$ BNC, "Decreto numero 230, por el cual se dispone la apertura de algunas Escuelas primarias y los sueldos de los Directores y Directoras", en El Porvenir, Cartagena, marzo 4 de 1903, p. 2.

35 BNC, "Decreto numero 230, por el cual se dispone la apertura de algunas Escuelas primarias y los sueldos de los Directores y Directoras", en El Porvenir, Cartagena, marzo 4 de 1903, p. 2; BNC, "Decreto numero 75, por el cual se introducen algunas modificaciones al presupuesto de gastos y se dictan algunas disposiciones sobre el ramo de instrucción pública", en Gaceta Departamental de Bolívar, Cartagena, febrero 17 de 1911, pp. 90-91. Estos sueldos, al menos, servían para tasar los productos de la canasta familiar que estaba tasada en $\$ 2,5$ diarios. 
sugirió un autor, venía a constituirse en ese sentido en la perpetuación de un "analfabetismo rural" al hacer de ella un privilegio para los municipios, distritos y provincias capitales ${ }^{36}$. La provincia de Cartagena, por los salarios altos de sus docentes, por su número superior de escuelas y alumnos matriculados con respectos a las otras jurisdicciones vecinas, consecuentemente, parecía ser ese núcleo privilegiado del aprendizaje básico en el Departamento de Bolívar ${ }^{37}$.

En efecto, en el Departamento de Bolívar estas disposiciones públicas (de orden nacional y departamental) no favorecían para nada una repartición equitativa de los recursos en todos los planteles educativos de sus distritos. Por el contrario, estas iniciativas políticas benefíciaban más a los cascos urbanos donde se mantuvo y hasta incrementó el número tanto de escuelas como de estudiantes matriculados (ver tabla 3). Asimismo, en poblaciones rurales como Santa Ana, Cereté, San Carlos, Turbaco, Arjona, San Estanislao, Clemencia, Las Piedras y Villanueva, lo común era la supresión de algunos de sus colegios, ya fuera de varones o niñas, por la falta de mobiliarios, tableros, pizarras, mapas, globos, textos y demás enseres indispensables para la existencia de las mismas. Una prueba de ello era que muchos niños debían cargar sillas de su casa para el colegio con tal de estar cómodos en sus escuelas ${ }^{38}$. En este sentido, vale la pena mencionar como el vocero de la

\footnotetext{
${ }^{36}$ I. Le Bot, Educación e ideología en Colombia, p. 15. Ver también A. Helg, La Educación en Colombia: 1918-1957, pp. 48-54. De hecho, muchos de los maestros graduados en las escuelas normales no querían impartir sus enseñanzas en las escuelas rurales por las difíciles condiciones para acceder a las mismas. M. de la Vega, Memoria que presenta el secretario de instrucción pública al señor gobernador del departamento en el año de 1896, p. 9.

${ }^{37}$ Ver esa preponderancia de las escuelas primarias de la Provincia de Cartagena con respecto a otros distritos del Departamento de Bolívar, como Mompox, El Carmen, Sincelejo, Chinú y Magangué, en la segunda década del siglo XX en F. Gómez, Memoria que presenta el director general de instrucción pública al Sr. gobernador del Departamento de Bolívar en el año de 1911; Fernando Gómez Pérez, Memoria del director general de instrucción pública al gobernador del Departamento de Bolívar en el año de 1913, Cartagena, Imp. de Mogollón, 1913, pp. 9-98; Memoria del director general de instrucción pública al gobernador de Bolivar en el año de 1914, Cartagena, Imp. de Mogollón, 1914, p. 7-109; BNC, Antonio J. de Irisarri, Informe general de instrucción pública al gobernador del departamento en el año de 1918, Cartagenpa, Imp. Departamental, 1918, pp. 7-15.

${ }^{38} \mathrm{BNC}$, "Decreto numero 913, por la cual se dictan algunas disposiciones en el ramo de instrucción pública",en Gaceta Departamental de Bolívar, Cartagena, enero 14 de 1915, p. 4643; "Informe del inspector provincia de instrucción pública del Departamento de Bolívar", en Gaceta Departamental de Bolivar, Cartagena, enero 12 de 1912, pp. 37-39; BNC, "Decreto 461, por el cual se suprimen unas escuelas", en Gaceta Departamental de Bolivar, Cartagena, octubre 9 de 1909, p. 37; BNC, "Sección de instrucción pública. Visita pasada a la escuela oficial de niñas de Cerete", en Gaceta Departamental de Bolivar, Cartagena, enero 4 de 1916, p. 5834; BNC, "Sección de instrucción pública. Visita pasada a la escuela de niñas de San Carlos", en Gaceta Departamental de Bolivar, Cartagena, enero 7 de 1916, p. 5842; BNC, "Informe sobre la marcha de la instrucción pública primaria en Cartagena", en Gaceta Departamental de Bolivar, Cartagena, mayo 4 de 1910, p. 614; "Informe de instrucción pública de la Provincia del Carmen"; BNC, "Visita pasada a las escuelas públicas de providencia", en Gaceta Departamental de Bolívar, Cartagena, junio 4 de 1910, p. 679. Mientras que, ciertamente, en el casco urbano de la Provincia de Cartagena tan sólo se registraba la clausura de la escuela de varones de el cabrero y, del mismo modo, la conversión del colegio de niñas del mismo lugar en alternada, la cual debía ser dirigida por la señorita Rebeca García. BNC, "Decreto numero 1221, por el cual se clausura una escuela y se convierte otra en alternada", en Gaceta Departamental de Bolivar, Cartagena, septiembre 23 de 1915, p. 5494.
} 
comunidad de Santa Ana, Antonio Pombo H., informaba sobre tal situación y tales anormalidades en el año de 1913:

En la población de Santa Ana hay una casa construida por el pueblo de su propio peculio con el objeto exclusivo de fabricar albergue a la escuela donde debían recibir instrucción los hijos de aquel hogar (...) Es el caso que allí no hay de escuelas ni la tablilla y a duras penas si hay más de cinco niños de ambos sexos, debido a que nadie se atreve a llevar allí niño alguno, por las siguientes razones:

En la sala principal de la casa hay una cantina y todas las borracheras del pueblo con sus correspondientes escándalos salen de allí - en el corredor se encuentra una sastrería dirigida por una hembra que corta y cose ropa interior y exterior de hombre; previa las medidas que toma en presencia de los niños, en el interior se encuentra una pulpería y en el conjunto tenemos parrandones, bochinches y paseos escandalosos de hombres y hembras a los pueblos y caseríos vecinos ${ }^{39}$.

De modo que con la Ley Antonio José Uribe de 1903, si bien los departamentos estaban facultados para organizar la educación primaria en todos sus distritos, veredas, municipios y ciudades, lo es también el hecho de que había un mayor interés por privilegiar las escuelas urbanas. En el Departamento de Bolívar, por ejemplo, fue en la provincia de Cartagena donde hubo más iniciativas departamentales para construir establecimientos de aprendizaje, financiar concursos para la realización de textos escolares, pagar a los maestros y acceder a locales propios para la enseñanza. Tanto fue así que, incluso, en algunas ocasiones se subvencionaban con fondos del tesoro departamental instituciones privadas como el Colegio de Nuestra Señora del Carmen, San Pedro Claver, San Pedro Apóstol, La Esperanza, Biffi y Pio X, los cuales sesionaban en esta localidad a principios del siglo XX. Estas ayudas a su vez iban desde la adjudicación de licencias para su entrada nuevamente en funcionamiento, como sucedió con el Colegio Fernández Madrid y de Heredia en 1903, hasta la delegación de \$100 mensuales para garantizar las normales actividades académicas en el Colegio Pio X y San Pedro Claver ${ }^{40}$. En efecto, la provincia de Cartagena terminaría siendo la capital de la instrucción pública primaria del Departamento de Bolívar a principios del siglo XX.

${ }^{39}$ BNC, “Escuela o cantina?”, en El Verbo, Cartagena, Septiembre 2 de 1913. Algunas de estas quejas también podemos encontrarlas en: BNC, “¿Escuela o caballeriza?, en El Verbo, Cartagena, Agosto 8 de 1913; BNC, "Por la redención de los pueblos", en Alma nueva, Cartagena, junio 2 de 1912; BNC, "Miserias escolares", en Orto, Magangué, junio 26 de 1910; BNC, "La cultura popular. Nuestra instrucción primaria”, en El Porvenir, Cartagena, marzo 12 de 1910.

${ }^{40}$ BNC, "Ordenanza numero 24, sobre auxilio a plantel de educación para señoritas. El colegio Pio X", en Gaceta Departamental de Bolivar, Cartagena, abril 20 de 1912; BNC, "Nota y contestación sobre auxilio al Colegio San Pedro Claver", en Gaceta Departamental de Bolivar, Cartagena, mayo 7 de 1910, p. 23; BNC, "Colegio de Heredia", en El Porvenir, Cartagena, febrero 8 de 1903; BNC, "Decreto Numero 230, sobre reapertura del Colegio Fernández de Madrid", en El Porvenir, Cartagena, marzo 1 de 1903; BNC, "Resolución numero 173 de 1910, por la cual se concede una facultad al Colegio San Pedro Claver", en Gaceta Departamental de Bolivar, Cartagena, octubre 29 de 1910, p. 899. J. Urueta y E. Piñeres, Cartagena y sus cercanías, p. 271. 


\section{La condición social de los estudiantes}

En la provincia de Cartagena había entonces un total de 52 escuelas de enseñanza primaria en 1911, donde acudían diariamente 4.314 alumnos, quienes por lo general hacían parte de las clases más "pudientes". En efecto, muchos de los estudiantes que asistían a la jornada de la mañana o la tarde estaban desprovistos de cualquier tipo de actividad laboral, puesto que gozaban de un buen apoyo económico familiar para desarrollar sus estudios y despreocuparse por trabajar. Esto hacia que este tipo de escolares terminaran satisfactoriamente sus estudios y aspiraran a entrar a la Universidad de Bolívar una vez concluyera su ciclo de educación básica ${ }^{41}$. Por el contario, los alumnos de la jornada nocturna, quienes dedicaban un porcentaje de su tiempo a actividades laborales (ver tabla 4), difícilmente, concluían su ciclo de formación académica. En consecuencia, la educación primaria acababa siendo un asunto exclusivo para los escolares pudientes que no se vieron en la necesidad de matricularse en las dos escuelas nocturnas que sesionaban en la ciudad, ya fuese la ubicada en el barrio la Catedral, a cargo de Epifanio González P., o la ubicada en el barrio de Getsemaní, dirigida por Fidel Gómez y Duque, donde lo común era que los estudiantes matriculados tuvieran las siguientes características laborales: ${ }^{42}$

No obstante, a diferencia de los estudiantes matriculados en las escuelas nocturnas, los "alumnos pudientes" de la jornada de la mañana y la tarde eran descendientes de familias acomodadas en la provincia de Cartagena, como por ejemplo: los Vélez, los Gómez, los Núñez, los del Valle, los Irisarri, los Martínez, los Azuaga, los Blanco, los Barraza, los Piñeres, entre otros apellidos, muy familiares con la lista de nombres de profesionales, abogados, intelectuales, médicos y personas reconocibles de la ciudad ${ }^{43}$. En efecto, eran hijos de algunos de los representantes de la elite cartagenera que contaban con los recursos necesarios para subvencionar el pago trimestral o semestral de las matriculas. También a este tipo de estudiantes se les concedieron becas como a Germán Gutiérrez de Piñeres y Francisco de Sotomayor ${ }^{44}$, cuyas vidas académicas en las escuelas primarias cartageneras

${ }^{41}$ Situación diferente se presentaba en los estudiantes de padres agricultores o de condición humilde que por lo general eran enviados a desarrollar actividades agrícolas y domesticas y se les dificultaba asistir a las escuelas. "Por la redención de los pueblos"; J. Abello, Memoria que presenta el secretario de instrucción pública al señor gobernador del Departamento de Bolívar, p. 12.

${ }^{42}$ J. Urueta y E. Piñeres, Cartagena y sus cercanías, p. 234. Es menester anotar que, además de esas instituciones, empezaría a funcionar también una escuela nocturna en el barrio San Diego y otra en el Pie de la Popa en el año de 1911. BNC, "Escuelas nocturnas", en El Liberal, Cartagena, marzo 12 de 1911.

43 J. Urueta y E. Piñeres, Cartagena y sus cercanías, pp. 254-255, 262-263. Algunos de estos apellidos, por ejemplo, coincidían con los nombres de los estudiantes que están realizando actividades escolares para saludar el centenario de la Provincia de Cartagena. Consúltese en ese sentido el listado de estudiantes inscritos en el Colegio Martínez Olier, quienes aparecían como autores de una cartilla patriótica dedicada a la independencia de Cartagena. Los mártires de Cartagena: anagramas de los patriotas fusilados por la espalda el 24 de febrero de 1816, al pie de la muralla occidental de la plaza del matadero (lienzo situado al norte del reloj público), Cartagena, Colegio Martínez Olier, Tip. El Esfuerzo, 11 de noviembre de 1911, 84 pp. (Este texto fue consultado sección de libros raros y manuscritos de la Biblioteca Luís Ángel Arango).

44 J. Abello, Memoria que presenta el secretario de instrucción pública al señor gobernador del Departamento de Bolívar en el año de 1894, p. 52. 
estuvieron libre de toda preocupación económica por ser descendientes de dos de las figuras más representativas de la independencia como Germán Gutiérrez de Piñeres y Juan Fernández Sotomayor y Picón. Los escolares de los establecimientos elementales, en resumidas, eran miembros de las estirpes más respetables y con más prestancia social, económica y política ${ }^{45}$.

Tabla $4^{46}$

Balance demostrativo de los estudiantes matriculados en la Escuela Nocturna de Cartagena, por nombres, edades y oficios, en el año de 1908

\begin{tabular}{|l|c|c|c|c|c|}
\hline \multicolumn{1}{|c|}{ Nombre } & Edad & Oficios & Nombre & Edad & Oficio \\
\hline Francisco Acosta & 14 & Doméstico & M. J. Ruiz & 15 & Doméstico \\
\hline Sebastián Raillo & 20 & Carpintero & David Ruiz & 9 & Hogareños \\
\hline Agustín Raillo & 18 & Carpintero & Mauricio Joves & 13 & Jornalero \\
\hline Camilo Lamadrid & 19 & Albañil & Pablo Joves & 13 & Hogareños \\
\hline Matías Sierra & 22 & Cocinero & Rubén Díaz & 14 & Jornalero \\
\hline Julio Díaz & 23 & Domésticos & Carmelo Jailach & 13 & Hogareños \\
\hline Clemente Martínez & 24 & Domésticos & M. Antero Jailach & 12 & Hogareños \\
\hline Fernando Meza & 14 & Agricultor & Candido Fernández & 15 & Jornalero \\
\hline Jesús M. Niera & 15 & Agricultor & Henrique Grandett & 11 & Hogareños \\
\hline José Ibarra & 19 & Jornalero & Nicanor Pallares & 9 & Hogareños \\
\hline Máximo Pereira & 11 & Hogareños & Salvador Pacheco & 20 & Doméstico \\
\hline Alberto Joves & 13 & Hogareños & Hilario Vázquez & 11 & Hogareños \\
\hline Erasmo Barón & 11 & Agricultor & Manuel Machado & 14 & Jornalero \\
\hline Adriano Barón & 16 & Agricultor & Saturnino Martínez & 18 & Platero \\
\hline Hortensio Tapia & 12 & Hogareños & Pedro Morales & 16 & Jornalero \\
\hline Faustino Vázquez & 19 & --- & Jesús M. Segura & 13 & Doméstico \\
\hline Rafael Lara & 11 & Hogareños & Andrés Ceballos & 15 & Doméstico \\
\hline Urbano Padilla & 16 & Agricultor & Manuel Murillo & 15 & Músico \\
\hline \multicolumn{1}{|c|}{ Ramón Martínez } & 12 & Hogareño & Javito Rodríguez & 8 & Doméstico \\
\hline Florentí Castellanos & 14 & Jornalero & Manuel Vega & 15 & Agricultor \\
\hline
\end{tabular}

Además, muchos de los "estudiantes pudientes" incluso preferían estudiar en instituciones privadas, como por ejemplo, el Colegio Martínez Olier, cuyo valor de la matricula no debía ser tan económico si tenemos en cuenta que era la única institución ajena a todo tipo de

\footnotetext{
${ }^{45}$ Algo no muy novedoso si tenemos en cuenta que en las "escuelas de primeras letras" siempre se había favorecido la entrada de los "hijos de los nobles" a las mismas en la Provincia de Cartagena a finales del siglo XVIII y en el transcurso del XIX. María T. Ripoll, La elite en Cartagena y su tránsito a la república. Revolución política sin renovación social, Bogotá, Uniandes, 2006, p. 10.

${ }^{46}$ Fuente: "Cuadro demostrativo de la matrícula y el movimiento de la escuela nocturna número 154 en el mes de enero de 1908", en Archivo Histórico de Cartagena (Colombia), Sección Gobernación (manuscritos), Fondo de Educación, tomo 19, Años: 1834-1939, Cartagena, febrero 4 de 1908.
} 
subvenciones públicas ${ }^{47}$. En las escuelas privadas, frecuentemente, el pago semestral de la mensualidad (por seis meses) no descendía de los \$100,oo, sin incluir la indumentaria y los enseres $^{48}$, cifra exagerada para un estudiante proveniente de los estratos humildes, hijo de padre y madre artesano o trabajador doméstico, quienes no ganaban más de $\$ 2$,oo diarios $^{49}$. Estos alumnos de estratos humildes por sus precarias condiciones económicas no tenían entonces la facilidad de acceder a instituciones públicas y privadas donde, aparte del pago de la matricula, debían comprar uniformes, utensilios y materiales de enseñanza que no se les proporcionaban. De hecho en una nota periodística se hacia una crítica contra este tipo de educación que parecía ser sólo un privilegio para los "alumnos pudientes" con una favorable posición económica, política y social:

Va cada día siendo más costosa la enseñanza en los colegios públicos que en los particulares, debido al sin número de exigencias, y a las frecuentes contribuciones a escote para pianos - que por ninguna parte se ve-, en maceteras, flores, estuches para obsequiar al señor Director en el día de su cumpleaños.

Acabamos de ver una cuenta de lo que vale el uniforme de las alumnas de la Anexa a la Normal de Señoritas, que asciende a la suma de Cuatrocientos Pesos, siendo la tela de mala clase y costando solo sesenta pesos el sombrero que cargan en el doble. ¿De dónde ha nacido ese derecho de la directora de la Anexa a monopolizar ella la costosa confección de los vestidos? $[\ldots]^{50}$.

Como se deduce, la entrada a las escuelas de básica primaria en la jornada de la mañana o la tarde, ya fuese pública o privada, no era un asunto poco cuantioso para las familias cartageneras. La educación primaria, por el contrario, constituía un privilegio para los estudiantes cuyos padres tenían una profesión, un trabajo o unas condiciones económicas favorables para pagar los gastos educativos de sus hijos. Algunos de estos gastos, incluso, se incrementaban en etapas de conmemoraciones políticas, como la del centenario, al exigirse a los estudiantes como tareas escolares construir carrozas, ornamentaciones, concursos sobre textos y planos relativos a la historia de Cartagena que demandaban recursos para la compra de los materiales ${ }^{51}$. Así pues, la formación del ciudadano en los establecimientos de instrucción pública no involucraba a todos los niños y jóvenes, pues necesitaban pagar los altos costos de la educación, algo casi imposible para poder acceder a

47 Este colegio que va hacer uno de los más representativos en la celebración del centenario de la independencia de Cartagena, fue fundado el 18 de marzo de 1884 por su director Lázaro Martínez, quien del mismo modo se complacía en decir que su institución se había financiado y logrado mantener con sus propios recursos. J.. Urueta y E. Piñeres, Cartagena y sus cercanías, p. 281.

${ }^{48}$ BNC, "Colegio de San Pedro Claver. Pensiones", en El Porvenir, Cartagena, enero 9 de 1903; "Colegio Biffi”, en El Porvenir, Cartagena, enero 9 de 1903.

${ }^{49}$ El promedio de los salarios mensuales de un obrero o un trabajador domestico oscilaba entre los $\$ 31,00$ y 50,oo, estipendios que debían servir también para cubrir los costos de la canasta familiar que tenía un valor aproximado de $\$ 2,20$. Sergio Paolo Solano, "Formación de los trabajadores fabriles en el Caribe colombiano", en El Taller de la Historia No 1, Cartagena, Universidad de Cartagena, 2001, pp. 113-114.

${ }^{50}$ BNC, “Enseñanza gratuita”, en La Opinión, Cartagena, abril 29 de 1916.

${ }^{51}$ BNC, "1811-centenario de Cartagena-1911. Mapa de la Antigua Provincia de Cartagena de Indias, realizado por los alumnos del Colegio Martínez Olier”, en El Porvenir, Cartagena, febrero 12 de 1911. 
uno de los cupos escolares. No obstante, independientemente de sus exclusiones, los planteles de enseñanza primaria empezaban a ser definidos como espacios ideológicos desde donde debía incentivarse el amor patrio por la república colombiana, por lo que entrar a una de esas instituciones educativas elementales constituía un primer paso para reconocerse como ciudadano colombiano ${ }^{52}$.

\section{La escuela reformada: la educación del ciudadano en la Provincia de Cartagena a principios del siglo $\mathrm{XX}$}

En este sentido, la categoría de ciudadano colombiano proveniente de la reglamentación de la educación pública en la Constitución Política de 1886, donde se ordenaba que la religión católica era un instrumento útil y oportuno para definir y formar la "calidad de nacional colombiano" en los estudiantes, hacia de las escuelas los escenarios de trasmisión de la pedagogía cívica asociada a la idea del buen cristiano que era una de las características del "hombre perfecto" 53 . La religión católica, apostólica y romana, en efecto, constituía la base ideológica desde la cual estaba siendo pensado, formado y educado ese modelo de "hombre ideal", cuya característica esencial debía ser la identificación con la conciencia, los ritos y principios católicos de la religiosidad de la república. Una muestra de ello era que los alumnos estaban en la obligación de asistir y participar en la santa misa, santificar las fiestas, confesarse y rezar el Padre nuestro y el ave María en público antes de comenzar cualquier actividad académica $^{54}$. Por ello, según lo expresado en los artículos 12 y 13 del concordato de 1887, la educación y los textos escolares quedaban bajo la organización y supervisión de los prelados eclesiásticos para evitar la propagación de ideas contrarias a los dogmas de la iglesia cristiana ${ }^{55}$. Así pues, este prospecto de "ciudadano católico" para acceder a la "calidad de nacional colombiano" necesitaba nada más que “(...) vivir sometidos a la Constitución y a las leyes, y respetar y obedecer a las autoridades" eclesiásticas $^{56}$. A los colegios, por lo tanto, les correspondía la misión de “(...) formar a esos hombres, es decir, buenos ciudadanos de una república cristiana, patriótica de carácter independiente y libre, ante todo iniciados en la disciplina de su propia educación que amen el trabajo y que posean por lo menos los conocimientos más indispensables para sostener en su respectivo Estado la lucha por la asistencia (...),57.

\footnotetext{
52 "La escuela primaria".

${ }^{53}$ M. Pombo y J. Guerra, Constituciones de Colombia, tomo IV, p. 216. Del mismo modo ver Fernando de la Vega, "La constitución del 86. Su proceso íntimo", en Boletín Historial No 94, Cartagena, Academia de Historia de Cartagena, 1946, p. 14.

${ }^{54}$ Soledad Acosta de Samper, Domingos de la familia cristiana: evangelios, prácticas y conversaciones sobre religión, París, Garnier, 1896. Sobre el caso específico de Cartagena ver: "Carta Eclesiástica de su Santidad Pío X”, en Archivo Eclesiástico de Cartagena, Pastoral colectiva, documento oficial, № 76 , Cartagena, Tip. Pontificia de San José, 1905, p. 28.

55 Jaime Jaramillo Uribe, "El proceso de la educación en Colombia, del Virreinato a la época contemporánea”, en Manual de historia de Colombia, tomo III, Bogotá, Instituto Colombiano de Cultura, 1982, p. 279.

${ }^{56}$ M. Pombo y J. Guerra, Constituciones de Colombia, tomo IV, p. 210.

${ }^{57}$ BNC, “Algo sobre educación en Colombia”, en El Porvenir, Cartagena, enero 7 de 1903.
} 
No obstante, esta conceptualización de las escuelas como espacios pedagógicos destinados a la preparación religiosa del ciudadano sería reformada a principios del siglo XX. Tras la emisión en 1903 de la Ley Antonio José Uribe, el ciudadano va a ser concebido de una nueva manera, como un hombre productivo, al lado del buen cristiano, en tanto para acceder al atributo de la ciudadanía debía demostrar estar instruido en los conocimientos que le habilitaban para la agricultura, el comercio y las industrias. Este sujeto político debía instruirse entonces en las artes útiles (agricultura, contabilidad, aritmética, zootecnia y los idiomas vivos), para formarse profesionalmente y más tarde llegar a ocupar las funciones públicas más lucrativas y dignificantes en la patria ${ }^{58}$. Esta nueva filosofía del ciudadano hacia de las escuelas de básica primaria un laboratorio de actividades pedagógicas, en tanto en ellas no sólo habrían de trasmitirse los conocimientos útiles para formar al futuro empresario, industrial y comerciante, sino que también estaba estipulado el desarrollo de clases de dibujo, artes, costura y bordados a través de las cuales los estudiantes debían trabajar en sus espacios educativos haciendo artesanías en provecho del incremento de los fondos departamentales ${ }^{59}$.

Un buen ejemplo de lo anterior lo constituían las escuelas primarias de ambos sexos y el Colegio Nuestra Señora del Carmen de Cartagena, donde los educandos eran instruidos para confeccionar sombreros, pellones y alpargatas, bobinas y cachuchas, hamacas y tejidos, entre otras manufacturas propias del conocimiento agrícola manual, cuyos recursos obtenidos de la venta debían contribuir al mejoramiento de orfelinatos, hospitales e incrementar los fondos departamentales ${ }^{60}$. Este trabajo artesanal de los alumnos realizado y socializado en las escuelas era una manera de contribuir al desarrollo de la localidad, por lo que terminaban apropiándose y poniendo en escena cierto sentido de pertenencia social por el territorio donde residían ${ }^{61}$. Así pues, este tipo de conocimientos y tareas escolares abría la posibilidad de elaborar una noción de ciudadanía de dimensiones más locales, asociada al adelanto cultural y la pertenencia cívica por la patria local. Por ello, en la provincia de

${ }^{58}$ BNC, "Ley 39 de 1903 sobre instrucción pública", en Registro de Bolívar, Cartagena, diciembre 22 de 1903. Ministerio de Instrucción Pública, Código de instrucción pública de Colombia, Bogotá, Imp. Nacional, 1911, pp. VI-XII. BNC, "Decreto numero 220, por el cual se reglamentan las escuelas superiores del Departamento de Bolívar", en Gaceta Departamental de Bolívar, Cartagena, mayo 26 de 1911; BNC, "Ley 38 de 1914, sobre enseñanza de la agricultura", en Gaceta Departamental de Bolívar, Cartagena, noviembre 5 de 1914.

59 BNC, "Ley 38 de 1914, sobre enseñanza de la agricultura”, en Gaceta Departamental de Bolívar, Cartagena, noviembre 5 de 1914. También ver "Ordenanza numero 46, por la cual se abren clases de bordado y modistería en varios establecimientos de educación”, en Gaceta Departamental de Bolívar, Cartagena, mayo 1 de 1912.

${ }^{60} \mathrm{BNC}$, "Ordenanza numero 62, por la cual se dictan varias disposiciones en el ramo de instrucción pública”, en Gaceta Departamental de Bolívar, Cartagena, mayo 15 de 1912; B.N.C., "Decreto numero 131, por el cual se abren unos cursos en el Colegio Nuestra Señora del Carmen y se hacen unos nombramientos", en Gaceta Departamental de Bolivar, Cartagena, marzo 4 de 1913.

${ }^{61}$ Algo muy similar a lo que Marcelo Carmagnani y Alicia Hernández Chávez han ilustrado como la ciudadanía orgánica para hacer alusión al sentimiento de pertenencia por el lugar donde radican, laboran y ejercen sus acciones sociales, políticas y culturales determinados individuos o grupos sociales para incentivar el desarrollo de su vecindad y adscribirse a la misma. Marcelo Carmagnani y Alicia Hernández, "La ciudadanía orgánica mexicana, 1850-1910", en H. Sabato, Ciudadanía política y la formación de las naciones, pp. 373 y ss. 
Cartagena, cuanto se estaban realizando actividades artísticas e históricas para celebrar el centenario, el moderno concepto de escuela reconocía el estudio como la fuente de los ideales progresista de la patria:

Con el Estudio se hace una Patria nueva, grande, fuerte, poderosa, leal, noble, sincera, que responda al espíritu del siglo, a las corrientes progresistas, a las imposiciones modernas: una Patria que no se humille con el servilismo del esclavo, no se levante con el espíritu gesto del tirano; una Patria de cuyo seno arranquen pensamientos altruistas y vigorosos, que cual potente faro en noche nebulosa, ilumine con radiosa claridad el vasto mar de la inteligencia. Con el Estudio de las ciencias, leyes, y artes, aplicadas a la agricultura se consigue formar una Patria nueva, prospera y feliz, una Patria única, donde convivan seres de cerebros sanos y corazones puros que sientan hondo y piensen alto $(\ldots)^{62}$.

Así, en la provincia de Cartagena, al mismo tiempo que evolucionaba el número de colegios y alumnos matriculados a principios del siglo XX, la escuela moderna implicaba una preparación religiosa, artística e intelectual de los escolares. Por ello, en 1911, cuando los estudiantes preparaban sus representaciones artísticas, literarias y científicas para saludar el centenario, el pensum de las escuelas de enseñanza superior primaria seria reorganizado por el gobierno departamental en función de tal festividad, en la que debía exhibirse en artes y decorados el progreso de la ciudad. En el currículo escolar, por ejemplo, llamaba la atención, por un lado, la repetición en tres ocasiones del curso de historia patria sobre hechos y personajes notables de la emancipación y por otro, la iniciativa por desarrollar nociones de geografía departamental e incluir lecciones de dibujo objetivo y geometría plana ${ }^{63}$. Esta organización curricular en las escuelas se dio con la finalidad de enseñar a los educandos a elogiar los acontecimientos, los personajes y la autonomía política lograda el once de noviembre de 1811 como simbología del adelanto cultural de la patria cartagenera (ver cuadro 5). A los estudiantes, por lo tanto, les correspondía el deber de interiorizar los conocimientos patrios para descubrir, imaginar y fantasear ese pasado, con lo cual daban muestras de su amor y pertenecía cívica por los eventos épicos de la patria local. Algunas de estas manifestaciones de "amor patrio" se evidenciaron en la realización de grabados, retratos, cartillas patrias y mapas en honor a los mártires de la independencia de Cartagena, como el plano ofrecido por los alumnos del Colegio Martínez Olier en 1911.

El énfasis en la historia patria, la geografía departamental, los dibujos objetivos y las lecciones de urbanidad, escritura y ejercicios ortográficos, confirmaban ese interés por

${ }^{62}$ BNC, "El estudio", en El Porvenir, Cartagena, enero 15 de 1910.

${ }^{63}$ BNC, "Decreto numero 220, por el cual se reglamentan las escuelas superiores del Departamento de Bolívar", en Gaceta Departamental de Bolivar, Cartagena, mayo 26 de 1911; BNC, "La fiesta de la bandera nacional. Hermoso proyecto para el centenario de Cartagena", en El Porvenir, Cartagena, abril 9 de 1911. "La fiesta de la bandera nacional. Hermoso proyecto para el centenario de Cartagena", y "El centenario de Cartagena en la Cámara de Representantes", en El Porvenir, Cartagena, octubre 31 de 1911. 
enseñar a los estudiantes a leer, escribir, imaginar, recordar y dar cierta lógica a los sucesos del pasado. Estas herramientas eruditas serían utilizadas por ellos para redescubrir y construir la memoria independentista de la ciudad, la del once de noviembre como estandarte de la independencia local y nacional, al hacer pequeñas composiciones orales y escritas, entonaciones y acentuaciones, mapas y planos relativos a los personajes, las situaciones y la fecha del movimiento revolucionario de 1811(ver tabla 5). La dramatización de la historia estaba impregnada de esas técnicas de aprendizaje para asignarle a los muertos un lugar en el presente al simbolizarlos como "padres", "próceres", "mártires" e "hijos de la patria", por su sacrificio en pro de la independencia ${ }^{64}$. Las escuelas iban constituyéndose entonces en los espacios por excelencia para "amar a la patria", pues en estos laboratorios de instrucción oficial el futuro ciudadano debía empezar a glorificar, elogiar y representar los eventos épicos del pasado para dar muestras de pertenecía social con respecto a la personalidad histórica de su provincia.

Tabla $5^{65}$

Anagramas al "altar de la patria" con motivo del centenario de la independencia de Cartagena, ofrecidas por los estudiantes del Colegio Martínez Olier en 1911.

\begin{tabular}{|c|c|c|c|}
\hline $\mathbf{N}^{\mathbf{0}}$ & Alumno & Nombre del Mártir & Alegoría o Anagrama \\
\hline I & José J. Puello. & $\begin{array}{c}\text { José M} \text {. García de } \\
\text { Toledo. }\end{array}$ & "Che, deja todo y goza al morir" \\
\hline II & Pablo Vélez. & José Ma Portocarrero. & "Jamás corrió por el terror" \\
\hline III & Benedicto Barraza. & Martín Amador. & "Morir....., nada más" \\
\hline IV & Adolfo L. Pérez. & Pantaleón Germán Ribón. & "Nombran el genio, Patria" \\
\hline V & Efraín del Valle. & Manuel Aguiano. & "A un ángel me unía" \\
\hline VI & Reginaldo Pedroza. & Santiago Stuard. & "Nada....., tus glorias" \\
\hline VII & Benedicto Barraza. & Antonio José de Ayos. & "Ay! Todo se nos negó ya!" \\
\hline VIII & Luís R. Sánchez. & Miguel Díaz Granados. & "Alma Grande guió Dios" \\
\hline IX & Reginaldo Pedroza. & Manuel del Castillo Rada. & "Y del cielo tan ruda llama" \\
\hline $\mathbf{X}$ & Ismael Porto M. & $\begin{array}{c}\text { Manuel Rodríguez } \\
\text { Torices. }\end{array}$ & "Y muere Cristo regando luz" \\
\hline
\end{tabular}

Este trabajo artesanal de los estudiantes, además de representar su "amor patrio", demostraba de cierta manera el sentido de pertenencia y participación cívica en eventos y conmemoraciones locales como la del 11 de noviembre de 1911. De modo que, aparte del

\footnotetext{
${ }^{64}$ Michel de Certeau, La escritura de la historia, México, Universidad Iberoamericana, 2006, pp.116-118.

${ }^{65}$ Fuente: Los mártires de Cartagena: anagramas de los patriotas fusilados por la espalda el 24 de febrero de 1816, al pie de la muralla occidental de la plaza del matadero (lienzo situado al norte del reloj público), Cartagena, Colegio Martínez Olier-Tip. El Esfuerzo, 11 de noviembre de 1911. Bernardo Tovar Zambrano, "Porque los muertos mandan. El imaginario patriótico de la historia colombiana", en Carlos Miguel Ortiz y Bernardo Tovar Z. (comp.), Pensar el pasado, Bogotá, Archivo General de la NaciónUniversidad Nacional, 1997, pp. 125-169.
} 
sentido católico de la noción de "calidad nacional de colombianos", el concepto de ciudadanía poseía una clara dimensión local asociada a la recuperación, valoración y puesta en escena de la memoria local. Asimismo, esta dimensión local de la ciudadanía no desconocía la facultad productiva que debían poseer los estudiantes para alcanzar el ideal del hombre y del ciudadano deseable, definido como un sujeto provechoso. De allí la insistencia en las escuelas de que a los niños se les enseñara a realizar dichos trabajos tanto con la mano izquierda como con la derecha, para potencializar aún más las facultades físicas e intelectuales. Esto se evidencio en el decreto 304 de 1909, donde se exigía que los alumnos debían aprender a escribir con ambas manos:

Art. 1. La enseñanza de la escritura en las escuelas normales y primarias se dará haciendo los ejercicios a duplicados, a saber, uno con la mano derecha y otro con la izquierda.

Art. 4. (...) En cuanto a la mejora que se refiere esta resolución reformatoria de los reglamentos los maestros pondrán de manifiesto a los educados como, mediante el hábil manejo de ambas manos, puede decirse que el hombre se duplica físicamente y aún gana en lo intelectual, por lo que deben esforzarse en vencer la dificultad que encuentren en los ejercicios ${ }^{66}$.

En efecto, los ejercicios de escritura a duplicado y los trabajos artesanales de los estudiantes representaban, por un lado, la pertenencia cívica a la localidad y por otro, el sentido productivo del hombre moderno o lo que daba por llamarse "el proletariado de los bachilleres" ${ }^{67}$ en la Ley Orgánica de Instrucción Pública de 1903. Bajo esta consideración, precisamente, el Ministro de Instrucción Pública, Antonio José Uribe, definía la personalidad del "sujeto educado" como un hombre práctico y digno habilitado para el ejercicio de la agricultura, la industria fabril y el comercio ${ }^{68}$. De hecho, muchos de los estudiantes de los colegios elementales, al tiempo que desarrollaban sus actividades académicas en los establecimientos de educación básica, asistían igualmente a las escuelas de tejidos de sombreros, industrial y de artes u oficios para reforzar y especializar sus tareas $^{69}$. Con la Ley Antonio José Uribe, por lo tanto, vino a favorecerse una nueva conceptualización sobre los colegios elementales y superiores de la primaria como laboratorios de educación de un ciudadano productivo, decoroso e ilustrado en las nociones

${ }^{66}$ BNC, "Resolución numero 304 de 1909, por la cual se reglamenta la enseñanza de la escritura", en Gaceta Departamental de Bolívar, Cartagena, noviembre 20 de 1909.

${ }^{67}$ Ministerio de Instrucción Pública, Código de instrucción pública de Colombia, p. XV.

${ }^{68}$ Ministerio de Instrucción Pública, Código de instrucción pública de Colombia, pp.VI y X.

${ }^{69}$ BNC, "Decreto numero 221, por el cual se crea una Escuela de Tejidos de Sombrero", en Gaceta Departamental de Bolivar, Cartagena, mayo 18 de 1910; "Nueva industria. Nuevo campo para los hijos de esta ciudad", en El Porvenir, Cartagena, mayo 14 de 1910; "Decreto numero 531, por el cual se suprime la Escuela de Tejidos de Sombrero y se da destino a la partida votada para su sostenimiento", en Gaceta Departamental de Bolivar, Cartagena, diciembre 31 de 1910; "Ordenanza 63, por la cual se establece una Escuela de Artes y Oficios", en Gaceta Departamental de Bolivar, Cartagena, mayo 10 de 1911, p.364; "Ordenanza Numero 30 por la cual se establece una Escuela Industrial en Sincelejo", en Gaceta Departamental de Bolívar, Cartagena, abril 19 de 1915. 
básicas de religión, bienestar y progreso de la patria ${ }^{70}$, como quedaba esto demostrado en las reformas tanto locales como nacionales destinadas a incentivar el santo "amor por la patria", la productividad y la religiosidad en los futuros ciudadanos.

Tanto fue así que en 1911, ante la consideración de las escuelas como escenarios de representación del progreso y amor por la patria, el presidente de la Sociedad de Artesanos de la provincia de Cartagena, Prisco Pérez A., en carta dirigida al gobernador del Departamento de Bolívar, Rafael Calvo C., solicitaba el respaldo de éste para la inauguración de una Escuela de Artes y Oficios con tal de no olvidar y exhibir en ella las habilidades y la contribución al "progreso de la patria" de los artesanos de la ciudad. A quienes Prisco Pérez denominaba como la "magia negra" por los trabajos científicos, técnicos y de historia, adelantado por aquellos actores sociales que querían ganarse un espacio público en las celebraciones centenarias para no pasar desapercibidos en las festividades patrias de 1911:

Es una verdad incontrovertible que los adelantos científicos de una nación guardan relación directa y estrecha con los progresos industriales y artísticos de ella; de tal manera, que muy poco o nada avanzaran las ciencias allí donde las Industrias y las Artes permanezcan estacionarias ó en el más absoluto abandono. La Cirugía, la Física, la Química, la Electricidad y demás ciencias experimentales que viene asombrando al mundo con su mágico influjo, no dejara de ser para los hijos de Cartagena, algo así como las sorpresas de la Magia Negra (...).

Ya se avecina la gloriosa fecha en que esos hijos de Cartagena, orgullosos de sus glorias legendarias, van á rendir pleito homenaje á los ilustres varones que, inspirados en el más alto civismo, volaron hacia el cielo de los inmortales y escribieron con letras de oro purísimo las páginas más hermosas que registra la Historia de los países de América, al regar con su sangre generosa los montes y los valles de la Patria.

Magnificas, por decir lo menos, serán las festividades con que conmemoramos el primer centenario de nuestra emancipación política; pero vergüenza da decirlo-el anhelo de los Artesanos de la Heroica, el orgullo de los Hijos del trabajo, es decir: las manufacturas, las obras nacionales, que causen la admiración de propios y extraños y que son el mejor exponente de los adelantos de un pueblo, brillaran en esa fecha por su ausencia.

Estas y otras consideraciones igualmente ciertas é igualmente acerbas nos obligan á pedir á Ud., como respetuosamente lo pedimos, interponga toda la autoridad de que se halla investido, todos los destellos de su poderosa y bien cultivada inteligencia, toda la nobleza de su alma nada común y todo el prestigio de su nombre ilustre, para que la Asamblea Departamental y en su defecto el Gobierno Supremo de la Nación, contribuya á acentuar el matiz verdaderamente patriótico que deben ostentar las festividades de nuestro primer centenario, inaugurando oficialmente en Cartagena, el 11 de

${ }^{70}$ Por ello, la educación primaria debía estar orientada hacia la enseñanza de los conocimientos morales, intelectuales, cívicos y físicos. Ministerio de Instrucción Pública, Código de instrucción pública de Colombia, pp. 22-25. 
Noviembre de 1911, una Escuela de Artes y Oficios á estilo completamente moderno $^{71}$.

Como podemos analizar en la anterior comunicación de la "Sociedad de Artesanos", además de la crítica subyacente al gobernador por no tener en cuenta las habilidades de los artesanos en la programación cultural para saludar el centenario, Prisco Pérez veía con buenos ojos la construcción de una Escuela de Artes y Oficios para salir de ese olvido y hacer de tal festividad un asunto "verdaderamente patriótico". Asimismo, llama la atención la forma como implícitamente era conceptualizado lo "patriótico" como la capacidad de desarrollar avances científicos, industriales, artísticos y manufacturas en beneficio del progreso de la nación y de Cartagena, por lo que habría de hacerse necesario la edificación de planteles educativos destinados a la enseñanza y el mejoramiento de estas artes laborales. En definitiva, lo patriótico estaba íntimamente relacionado con la entrada y la preparación académica en los espacios educativos ${ }^{72}$. Por ello, aquella queja pública nos lleva a pensar que una de las misiones ideológicas de las escuelas, aparte de formar hombres útiles a la patria, era la de conceder cierto prestigio social a los educandos por sus labores escolares que engrandecían el sentido de la patria tanto local como nacional. De modo que, ciertamente, si bien en esta Escuela de Artes y Oficios no se iba a desarrollar el pensum académico aprobado para los establecimientos de primaria en 1911, cierto es el hecho también de que ambos escenarios educativos tenían por misión construir la identidad nacional y local del ciudadano en el primer centenario.

Por esta razón, en vísperas y posterior al centenario, hubo varias iniciativas departamentales por construir colegios en el casco urbano de la ciudad no sólo para avivar el amor patrio entre los alumnos, sino también para rehabilitar a los hombres que por sus errores pagaban condenas en las cárceles. Una muestra de ello lo constituye la instauración de diez escuelas primarias en las correccionales del Departamento de Bolívar, una de las cuales funcionaría en la casa de prisión y reclusión de Cartagena y las otras en las demás penitenciarías del circuito departamental. El objetivo de estos establecimientos era hacer de los reclusos hombres útiles, por lo que además de instruirlos en los idiomas, religión, historia, geografía, contabilidad, física, entre otras asignaturas, debían igualmente adiestrase en cuanto a la realización de tejidos y confecciones artísticas destinadas a la venta pública en estos mismos lugares ${ }^{73}$. Pero más allá de esta funcionalidad, la escuela debía servir asimismo para encausar su amor por la patria y para pretender pasar de la condición de "vagos", "holgazanes" y "gentes licenciosas" -como eran llamados en la prensa oficial- a ciudadanos dignos en la Provincia de Cartagena.

${ }^{71}$ F. Gómez, Memoria que presenta el director general de instrucción pública al Sr. gobernador del Departamento de Bolívar en el año de 1911, pp.39-40.

${ }^{72}$ Sobre esta relación entre patria, ciudadanía y escuela recomendamos el artículo de: Mario Carretero y Miriam Kriger, "¿Forjar patriotas o educar cosmopolitas? El pasado y el presente de la historia escolar en un mundo global", en Mario Carretero y James Voss (comps.), Aprender y pensar la historia, Buenos Aires, Amorrortu eds., 2004, pp. 71-98.

73 BNC, "Ordenanza número 4, por la cual se crean unas escuelas en las casas de prisión", en Gaceta Departamental de Bolivar, Cartagena, marzo 20 de 1914. 
Curiosamente, en 1903, cuando la educación primaria era reformada, en el Departamento de Bolívar también empezaban a ser reglamentadas una serie de disposiciones públicas en los códigos de policía sobre las conductas permitidas y prohibidas, en las que evidentemente se disponía que la no entrada de cualquier persona o su expulsión reiterativa de las escuelas, fábricas, iglesias u otros establecimientos públicos, era considerado "vagancia" y "holgazanería" por aquella época ${ }^{74}$. No obstante, la provincia de Cartagena no estaba exenta de esta tipificación de las prácticas cotidianas manifestadas en la legislación policiva (ver cuadro 6). Allí, por ejemplo, los inspectores de policía serían los encargados de reportar aquellas acciones consideradas "ociosas" y "poco productivas" como la pérdida del tiempo en las casas de juegos, las reiteradas idas a las cantinas o el estarse mucho tiempo sentado en las esquinas de una calle. Por ello, los educandos que siendo hijos de familia y pupilos no estuviesen matriculados en los colegios, públicos o privados, de artes o de oficios, también se les consideraba "vagos" en la legislación policiva $^{75}$. Asimismo, esta censura incumbía a los alumnos renuentes al cumplimiento de sus actividades educativas, los que no asistían a clases, los que fuesen expulsados, los indisciplinados y los que cometieran desordenes públicos de cualquier naturaleza ${ }^{76}$. Así pues, si bien la entrada a las escuelas primarias constituía el primer paso para acceder al reconocimiento de la ciudadanía, lo es también el hecho de que estar por fuera de ellas era exponerse a una marginalización del modelo de hombre y sociedad "deseable" a principios del siglo $\mathrm{XX}^{77}$.

De modo que como se deduce en el cuadro 6, la provincia de Cartagena además de convertirse en la capital departamental de la instrucción pública durante la celebración del centenario de la independencia, era el lugar donde la entrada a alguna de sus instituciones de la básica primaria facultaba a los escolares como sujetos dignos, notables y cultos de la patria política. No obstante, no asistir a los colegios constituía un buen motivo para ser objeto de calificativos por parte de la prensa como "vagos", "holgazanes", "mendigos", "licenciosos" y "ociosos" por no preparase estos educandos útilmente para la patria. Los juegos prohibidos y permitidos, así como las denominadas "conductas de vagancia", se constituyeron pues en la antítesis del discurso moderno del ciudadano al incorporar un nuevo lenguaje político que desconocía las practicas de diversión popular por no ser compatible con la filosofía escolar del periodo, aún cuando la no asistencia de algunos

\footnotetext{
${ }^{74}$ M. Dávila, Código de policía del departamento de Bolívar con las modificaciones introducidas por las ordenanzas posteriores á la 54 de 1892, pp. 209-213.

75 Rafael Calvo (comp.), Código de policía del Departamento de Bolívar, Cartagena, Imp. Departamental, 1930, p. 115.

${ }^{76}$ Sobre esta conceptualización ver: BNC, "la cultura de nuestro pueblo", en El Porvenir, Cartagena, marzo 16 de 1911, p. 3. Ivonne Bravo, Comportamientos ilícitos y mecanismos de control social en el Bolivar Grande, Cartagena, Premio Departamental de Cultura-Ministerio de Cultura, 1998, pp. 28 y ss.

77 No obstante, proporcional al concepto del "vago", los inspectores de policía castigaban a esos individuos vinculándolos a obras públicas, para de esta manera tratar a ellos de convertirlos en "sujetos productivos", por lo que los denominados "vagos" consolidaban la posibilidad de algún día llegar a adquirir cierto reconocimiento cívico. Pero lo más común era pasar de ciudadanos a vagos en una sociedad marcada por la exclusión y la indiferencia hacia viejas usanzas populares, como los juegos de suerte y azar. R. Calvo, Código de policía del Departamento de Bolívar, p. 112.
} 
escolares no sólo estaba determinada por tales diversiones, sino igualmente por las condiciones económicas no apropiadas para entrar a los planteles de enseñanza elemental.

\section{Tabla $6^{78}$}

Prácticas permitidas y prohibidas en la Provincia de Cartagena a finales del siglo XIX y principios del XX.

\begin{tabular}{|c|c|c|c|}
\hline $\mathrm{N}^{\mathrm{o}}$ & Conductas de vagancia & Juegos prohibidos & Juegos permitidos \\
\hline 1 & $\begin{array}{l}\text { Las personas que se } \\
\text { alimentan o subsisten con } \\
\text { dineros ilícitos. }\end{array}$ & $\begin{array}{c}\text { Juegos de suerte y azar: ruleta, } \\
\text { el macondo, ruedas de fortuna, } \\
\text { la bragueta, el boliche, las } \\
\text { barajas, entre otros. }\end{array}$ & $\begin{array}{l}\text { Rifas, loterías, carreras de } \\
\text { caballos y los juegos de gallos } \\
\text { con su respectivo permiso por } \\
\text { parte de las autoridades. }\end{array}$ \\
\hline 2 & $\begin{array}{l}\text { Los hombres que establezcan } \\
\text { relaciones constantes con } \\
\text { personas ociosas, viciosas y } \\
\text { de malas costumbres. }\end{array}$ & $\begin{array}{l}\text { Los juegos relacionados con } \\
\text { apuestas de dinero. }\end{array}$ & $\begin{array}{c}\text { Las diversiones encaminadas } \\
\text { hacia una obra de } \\
\text { beneficencia. }\end{array}$ \\
\hline 3 & $\begin{array}{l}\text { Los hombres y mujeres } \\
\text { escandalosos y } \sin \\
\text { educación. }\end{array}$ & $\begin{array}{l}\text { La asistencia de niños o } \\
\text { personas en estado de beodez a } \\
\text { las casas de juegos permitidos. }\end{array}$ & $\begin{array}{l}\text { Los juegos en clubes que } \\
\text { paguen el impuesto anual. }\end{array}$ \\
\hline 4 & $\begin{array}{l}\text { Los menores adultos, } \\
\text { sirvientes domésticos o } \\
\text { jornaleros entregados a los } \\
\text { juegos prohibidos }\end{array}$ & $\begin{array}{c}\text { El establecimiento y } \\
\text { desarrollo de } \\
\text { diversiones publicas } \\
\text { sin permiso de las autoridades. }\end{array}$ & $\begin{array}{c}\text { Las casas de juegos prohibidos } \\
\text { no dejaran entrar a los } \\
\text { menores, jornaleros o } \\
\text { aprendices. }\end{array}$ \\
\hline 5 & Las mujeres publicas & $\begin{array}{l}\text { Las diversiones en horas de } \\
\text { clase o trabajo. }\end{array}$ & $\begin{array}{l}\text { Los juegos se permiten sólo en } \\
\text { recintos privados. }\end{array}$ \\
\hline 6 & $\begin{array}{l}\text { Los oficiales, jornaleros, } \\
\text { aprendices y sirvientes con } \\
\text { un precario sueldo. }\end{array}$ & $\begin{array}{c}\text { Los juegos contrarios a la moral } \\
\text { y dignidad católica }\end{array}$ & $\begin{array}{l}\text { A los jugadores no se les } \\
\text { pueden pedir gabelas o } \\
\text { tributos. }\end{array}$ \\
\hline 7 & $\begin{array}{l}\text { Los estudiantes que no } \\
\text { asistan a clases y aquellos } \\
\text { que sean expulsados de los } \\
\text { colegios. }\end{array}$ & $\begin{array}{l}\text { Los juegos con manifestación } \\
\text { de golpes. }\end{array}$ & $\begin{array}{l}\text { Prohibido las apuestas en } \\
\text { dinero o especie. }\end{array}$ \\
\hline 8 & $\begin{array}{l}\text { Los que mendigan o } \\
\text { irrespeten a la policía }\end{array}$ & $\begin{array}{c}\text { La venta de licor o sustancia } \\
\text { alucinógena en las casas de } \\
\text { juegos permitidos }\end{array}$ & $\begin{array}{l}\text { Las galleras sólo funcionaran } \\
\text { en días feriados de las } 7 \text { de la } \\
\text { mañana a las } 6 \text { de la tarde }\end{array}$ \\
\hline 9 & $\begin{array}{l}\text { Los trabajadores } \\
\text { independientes, sin puesto de } \\
\text { trabajo fijo. }\end{array}$ & $\begin{array}{c}\text { Los juegos con manifestación } \\
\text { de injuria verbal. }\end{array}$ & $\begin{array}{l}\text { Las casa de juegos permitidos } \\
\text { serán revisadas } \\
\text { periódicamente por la policía }\end{array}$ \\
\hline 10 & Los embriagados y ladrones. & $\begin{array}{l}\text { El desarrollo reiterativo de } \\
\text { rifas, loterías, entre otras } \\
\text { apuestas. }\end{array}$ & $\begin{array}{l}\text { Prohibido cualquier tipo de } \\
\text { escándalos en las casas de } \\
\text { juegos permitidos. }\end{array}$ \\
\hline 11 & $\begin{array}{l}\text { Los condenados por ir a los } \\
\text { juegos prohibidos o por } \\
\text { abuso de juegos permitidos. }\end{array}$ & $\begin{array}{c}\text { Las diversiones públicas o } \\
\text { populares en las } \\
\text { conmemoraciones religiosas o } \\
\text { patrias }\end{array}$ & $\begin{array}{l}\text { Se cerrara el establecimiento } \\
\text { cuando estos falten a la norma }\end{array}$ \\
\hline
\end{tabular}

${ }^{78}$ Fuente: M. Dávila, Código de policía del departamento de Bolívar con las modificaciones introducidas por las ordenanzas posteriores á la 54 de 1892, pp. 209-213. De igual manera ver: Código de policía del departamento de Bolivar, Cartagena, Imp. Departamental, 1925, pp. 209-232; Código de policía del departamento de Bolivar, Cartagena, Imp. Departamental, 1925, pp.89-183; R. Calvo, Código de Policía del Departamento de Bolívar, pp.107-135. . 
Desde este punto de vista, el proyecto regenerador y conservador de formar el ciudadano desde las escuelas se tornaba excluyente, poco efectivo y muy acomodado al mundo de valores y simbología patrios de índole política. En consecuencia las escuelas, por todas las características anotadas, debieron ser los escenarios más importantes para supervisar, pensar, organizar y ejecutar la festividad política en honor al primer centenario de la independencia en 1911, pues era esta el ámbito intelectual por excelencia donde el "amor patrio" constituía una de las banderas de los proyectos educativos para llegar a ser reconocidos públicamente como ciudadanos.

\section{Algunas consideraciones finales}

Hace ya casi cien años, en 1911, durante la celebración del centenario de la independencia en la provincia de Cartagena, las autoridades locales vieron en la apertura de nuevas escuelas la representación de la trasformación política, el progreso y adelanto cultural de esta localidad en sus primeros cien años de vida republicana. En aquella ocasión, quizás por ser la primera festividad centenaria celebrada en esta ciudad, los dirigentes departamentales y locales se dieron a la tarea de afirmar y hacer de la provincia de Cartagena la capital de la instrucción pública en el Departamento de Bolívar. Allí, por ejemplo, fue el lugar donde más concurrían los niños y jóvenes a educarse, donde había más colegios elementales y donde los materiales y enseres educativos parecían no ser tan escasos. En perspectiva comparativa con lo registrado en otros periodos marcados por las guerras civiles como el de 1896-1902, donde tan sólo existían 19 instituciones básicas que en algunas ocasiones eran clausuradas por los secuelas de guerras como la de los Mil Días, las dos primeras décadas del siglo XX significaron un avance en cuanto al progreso educativo y cultural de Cartagena. Pero al mismo tiempo que se incrementaba el número de planteles educativos, también se incrementaba el número de estudiantes que no podían concurrir a ellas por la falta de recursos económicos que garantizaran su permanencia en esos espacios de formación. En este sentido, el proyecto de formar ciudadanos desde las escuelas terminaba inconcluso y se tornaba excluyente al no ofrecer una cobertura educativa amplia al gran número de niños y jóvenes, de estratos humildes y por lo general de las zonas rurales, quienes veían muchas veces interrumpidos sus estudios por la dedicación de gran parte de su tiempo a actividades laborales que les permitían subsistir. Esta realidad, no obstante, fue una de las deudas que dejaba el proyecto de obertura y progreso educativo propugnado y adelantado por los dirigentes cartageneros en la época del centenario.

Paradójicamente, los estudiantes que no pertenecían a alguna de las escuelas terminan siendo objeto de todo tipo de calificativos por la prensa oficial y los mismos dirigentes de la provincia de Cartagena, quienes los veían como vagos, holgazanes y mendigos al estar constantemente sentados en las esquinas de las calles, en las casas de juegos o en algún otro sitio no apropiado para un ciudadano educado y decente, pero desde donde los educandos de estratos humildes podían conseguir un espacio para laborar. Antes que brindar las condiciones para formar a esos "pequeños trabajadores", sin duda, la 
marginalización del ideal de sociedad deseable y la no afirmación del título de ciudadanía parecía ser la estrategia más indicada para reducir la escala de instrucción, de participación electoral y reconocimiento del atributo de ciudadano en aquellos actores sociales no adscritos a una institución educativa. Así pues, la educación pública y privada terminaba siendo un estatuto privilegiado para las "clases pudientes", para los alumnos que gozaban de una buena situación económica o de apoyo familiar para adelantar sus estudios. Cien años después de haberse logrado la independencia en la provincia de Cartagena, por ende, el proyecto de igualdad política decretado con el proceso de la emancipación en Cartagena seguía siendo una promesa al no garantizarse la formación, participación y apertura de espacios de discusión a los sectores menos favorecidos económicamente.

En este sentido, quizás cuando el presidente de la Sociedad de Artesanos, Prisco Pérez, solicitaba la creación de una Escuela de Artes y Oficios, la cual había sido clausurada en varias ocasiones por la falta de recursos para subvencionarla, lo hacía con el firme propósito de reclamar la obertura de un espacio político y educativo desde donde empezar a repensar el sentido demagógico, político y excluyente del proyecto de departamentalización de la educación decretado con la departamentalización la Ley Orgánica de Instrucción Pública de 1903. Sin duda alguna, los artesanos veían en su trabajo la posibilidad de reconocerse públicamente y de propender por el titulo de ciudadanía, por lo que, más allá de la definición formal del ciudadano como un sujeto productivo, católico, republicano y amante a la patria, estos actores sociales empezaban a hacerse participe en la discusión adelantada en torno al sentido de la educación como espacio democrático al reclamar la apertura de escuelas para socializar sus artes y oficios. Desde este punto de vista, las escuelas, además de la función social asignada como divulgadora de saberes y dispositivo ideológico de formación de ciudadanías, empezaba a ser objeto de cierta deliberación critica por los sectores no favorecidos con tal proyecto educativo y pedagogía cívica por su situación económica. Sin embargo, lo común era seguir observando el mayor número de estudiantes pertenecientes a las "clases pudientes" matriculados en las escuelas, dejándose así para la posteridad la entrada, participación y formación en los colegios de los sectores sociales más humildes de la ciudad.

Por ello, hoy cuando estamos a escasos años de conmemorar los primeros doscientos años de convivencia política y formación de ciudadanías, el proyecto del bicentenario de la independencia se debe constituir en un momento político y social propicio para hacer de la educación y las escuelas los espacios democráticos apropiados para formar diversos modelos de ciudadanía. La apertura de escuelas, la vinculación de diversos sectores sociales a la educación, la reformulación de los valores del ciudadano moderno y la no deserción escolar, por ejemplo, son algunos de los problemas que afronta la sociedad cartagenera del siglo XXI, los cuales demandan de un examen crítico en la agenda de la representación del progreso, engrandecimiento y trasformación política de la localidad con miras a la celebración del próximo bicentenario de la independencia. Hoy, en efecto, las conmemoraciones bicentenarias nos ponen ante el reto de reformular y superar las múltiples exclusiones, vulnerabilidades y definiciones demagógicas, religiosas, útiles y patrióticas de ciudadanía política que terminaron privando a un gran número de estudiantes la posibilidad de ser tenidos en cuenta como ciudadanos útiles a principios del siglo XX. 